\title{
Minimal epitope for Mannitou IgM on paucimannose-carrying glycoproteins
}

\section{Stefania Robakiewicz ${ }^{1 \#}$, Clarisse Bridot $^{1 \#}$, Sonia Serna ${ }^{2 \#}$, Ana Gimeno ${ }^{3}$, Begoña}

Echeverria $^{2}$, Sandra Delgado ${ }^{3}$, Jérôme de Ruyck ${ }^{1}$, Shubham Semwal ${ }^{1}$, Diego Charro $^{3}$, Ann Dansercoer ${ }^{4}$, Kenneth Verstraete ${ }^{4}$, Mikel Azkargorta ${ }^{3}$, Kim van Noort $^{5}$, Ruud Wilbers ${ }^{5}$, Savvas N. Savvides ${ }^{4}$, Nicola G. A. Abrescia ${ }^{3,6}$, Ana Arda ${ }^{3}$, Niels C. Reichardt ${ }^{2 \star}$, Jesús Jiménez-Barbero ${ }^{3,6 *}$ and Julie Bouckaert ${ }^{1}$ *

${ }^{1}$ Unité de Glycobiologie Structurale et Fonctionnelle, UMR 8576 du CNRS et Université de Lille, 50 Avenue Halley, 59650 Villeneuve d'Ascq, France;

${ }^{2}$ Glycotechnology Laboratory, Center for Cooperative Research in Biomaterials (CIC biomaGUNE), Basque Research and Technology Alliance (BRTA), Paseo Miramón 182, 20014 San Sebastian, Spain;

${ }^{3}$ CIC bioGUNE, Bizkaia Science and Technology Park, 48160 Derio, Spain;

${ }^{4}$ Unit for Structural Biology, VIB - UGent Center for Inflammation Research, Department of Biochemistry and Microbiology, Ghent University, Technologiepark 71, 9052 Ghent, Belgium;

5 Laboratory of Nematology, Plant Science Group, Wageningen University and Research, Droevendaalsesteeg 1, 6708 PB Wageningen, The Netherlands;

${ }^{6}$ IKERBASQUE, Basque Foundation for Science, 48009 Bilbao, Spain.

(C) The Author(s) 2021. Published by Oxford University Press. All rights reserved. For permissions, please e-mail: journals.permissions@oup.com 
\#First authors who have made equal contributions

* To whom correspondence may be addressed:

Niels Reichardt nreichardt@cicbiomagune.es

Jesús Jiménez-Barbero jibarbero@cicbiogune.es

Julie Bouckaert julie.bouckaert@univ-lille.fr

Running title: Binding by Mannitou IgM of paucimannose-carrying proteins

Keywords: core fucose / IgM / Mannitou / N-glycan / paucimannosidic epitopes 


\section{Abstract}

Paucimannosidic glycans are restricted to the core structure [ $\mathrm{Man}_{1-3} \mathrm{GlcNAc}_{2} \mathrm{Fuc}_{0-1}$ ] of $\mathrm{N}$-glycans and are rarely found in mammalian tissues. Yet, especially [Man ${ }_{2-}$ ${ }_{3} \mathrm{GlcNAc}_{2} \mathrm{Fuc}_{1}$ ] have been found significantly upregulated in tumors, including in colorectal and liver cancer. Mannitou $\operatorname{lgM}$ is a murine monoclonal antibody that was previously shown to recognise $\mathrm{Man}_{3} \mathrm{GlCNAc}_{2}$ with an almost exclusive selectivity, Here, we have sought the definition of the minimal glycan epitope of Mannitou $\operatorname{lgM}$, initiated by screening on a newly designed paucimannosidic glycan microarray. Among the best binders were $\mathrm{Man}_{3} \mathrm{GICNAc}_{2}$ and its $\alpha 1,6$ core-fucosylated variant, $\mathrm{Man}_{3} \mathrm{GlcNAc}_{2} \mathrm{Fuc}_{1}$. Unexpectedly and in contrast to earlier findings, Man ${ }_{5} \mathrm{GlcNAc}_{2}-$ type structures bind equally well and a large tolerance was observed for substitutions on the $\alpha 1,6$ arm. It was confirmed that any substitution on the single $\alpha 1,3$-linked mannose completely abolishes binding. Surface plasmon resonance for kinetic measurements of Mannitou IgM binding, either directly on the glycans or as presented on omega-1 and kappa-5 soluble egg antigens from the helminth parasite Schistosoma mansoni, showed submicromolar affinities. To characterize the epitope in greater and atomic detail, saturation transfer difference nuclear magnetic resonance spectroscopy was performed with the Mannitou antigen-binding fragment. The STD-NMR data demonstrated the strongest interactions with the aliphatic protons $\mathrm{H} 1$ and $\mathrm{H} 2$ of the $\alpha 1-3$-linked mannose, and weaker imprints on its $\mathrm{H} 3, \mathrm{H} 4$ and H5 protons. In conclúsion, Mannitou IgM binding requires a non-substituted a1,3-linked mannose branch of paucimannose also on proteins, making it a highly specific tool for the distinction of concurrent human tumor-associated carbohydrate antigens.

\section{Introduction}

The biological importance of glycosylation in health and disease has long been established and continues to grow (Lau et al., 2007; Lauc et al., 2010; Taganna et al., 2011; Bruxelle et al., 2020). The glycoproteome reflects the overall 
cellular status since it participates either in modulation or mediation of a wide range of processes in physiological and pathophysiological conditions, i.e. cell adhesion, molecular trafficking and clearance, protein folding, receptor activation, signal transduction and endocytosis (Stambuk et al., 2020; Lau and Dennis, 2008). Protein glycosylation patterns are modified in various human diseases, including congenital disorders of glycosylation (Houdou and Foulquier, 2020), auto immune diseases such as rheumatoid arthritis (Magorivska et al., 2018) and systemic lupus erythematosus (Szabo et al., 2019), and in infectious diseases (Thaysen-Andersen et al., 2015). The ubiquity of glycosylation and its fundamental significance in practically every biological process exemplifies the immense potential of glycans as biomarkers (Reily et al., 2019; de Vroome et al., 2018).

The core structure of all eukaryotic $N$-glycans consists of two $N$-acetyl $\beta$ glucosamine (GlcNAc) and three mannose (Man) residues, $\mathrm{Man}_{3} \mathrm{GlcNAc}_{2}$, also termed paucimannosidic glycan (PMG) (Schachter, 2009). The early stages of $\mathrm{N}$ glycosylation are shared among all eukaryotes and include the generation of a lipidlinked oligosaccharide precursor $\mathrm{Gl}_{3} \mathrm{Man}_{9} \mathrm{GlcNAc}_{2}$-pyrophosphate-dolichol to nascent glycoproteins in the endoplasmic reticulum (Aebi et al., 2010). The second phase involves the processing of asparagine-linked $\mathrm{Gl}_{3} \mathrm{Man}_{9} \mathrm{GlcNAc}_{2}$ within the lumen of the endoplasmic reticulum up to $\mathrm{Man}_{5} \mathrm{GlcNAc}_{2}$ in the Golgi apparatus. This pathway diverges evolutionary in plants, invertebrates and vertebrates, that each process the $\mathrm{Man}_{5} \mathrm{GlcNAc}_{2}$ intermediate in different ways into high-mannose, hybrid, and complex $\mathrm{N}$-glycans. In humans, an enzyme in the Golgi apparatus, $\mathrm{N}$-acetyl $\beta 1$ 2-glucosaminyltransferase (GnT-I), transfers a GlcNAc residue on the $\alpha 1,3$-linked mannose of the $N$-glycan. Following the trimming of the $\alpha 1,6$ Man arm by $\alpha$ mannosidase-II, this hybrid glycan is finally truncated into a PMG by an $\mathrm{N}$-acetyl- $\beta$ hexosaminidase (Hex A or Hex B) (Tjondro et al., 2019). An alternative, GnT-I independent, truncation pathway has been shown to facilitate greatly the biogenesis of a1,6 core-fucosylated $\mathrm{Man}_{4} \mathrm{GlcNAc}_{2}$ and $\mathrm{Man}_{5} \mathrm{GlcNAc}_{2}$ in GnT-I-deficient Chinese hamster ovary cells (Lin et al., 1994).

Despite the great progress achieved in the field, rapid detection of alterations in the expression of specific $\mathrm{N}$-glycans associated with pathophysiological states is still challenging. Anti-carbohydrate antibodies lend a good diagnostic tool to this aim. 
Mannitou is a monoclonal mouse IgM, originally named Laz6-189, raised against a 130-kDa glycoprotein from the leech central nervous system (Flaster et al., 1983). It was subsequently characterized as being able to specifically recognize paucimannose-carrying glycoproteins (PMPs) (Bajt et al., 1990; Zipser et al., 2012). Since, other PMPs with important neurobiological functions have be detected using Mannitou, among others human neutrophil elastase (Loke et al., 2017), synapsin-1 (Simon et al., 2019) and AHNAK (Becker et al., 2019). Intriguing recent discoveries point to paucimannose $\mathrm{N}$-glycans (PMGs) as facilitators of an effective immune response during physiological and pathophysiological conditions (Loke et al., 2016).

A recent wide cancer glycomics analysis from human cancer cell lines and tissue samples illustrated that different cancer types and the disease progression stage can be stratified based on the distribution and ratios of paucimannosidic $N$ glycans (Chatterjee et al., 2019). Both the rare incidence of paucimannose $\mathrm{N}$ glycosylation in the extracellular environment and its upregulation to give potent signals and communicate with the immune system have made Mannitou a useful tool for the detection of paucimannose epitopes (Chatterjee et al., 2019; Becker et al., 2019; Dahmen et al., 2015; Thaysen-Andersen et al., 2015; Loke et al., 2017; Zipser et al., 2012; Simon et al., 2019). Paucimannose-carrying proteins are exposed on the plasma membrane of transforming cells as opposed to highmannose-carrying proteins predominantly hidden in the cytoplasm of normal cells (Loke et al., 2016), enabling their targeting by monoclonal antibodies such as Mannitou IgM. In this study, we highlight interaction regions on the Man3GlcNAc(Fuca1-6)GICNAc PMG with paratope residues of the Mannitou variable domains and demonstrate how specificity and affinity of Mannitou is finetuned to differentiate between paucimannosidic and other $\mathrm{N}$-glycans on proteins.

\section{Results}

\section{Ligand screening with microarrays of defined paucimannose N-glycans}

Initially, the characterization of carbohydrate binding profile of Mannitou IgM was performed with the help of glycan microarrays, a technique that enables the high-throughput screening of protein-carbohydrate interactions. Mannitou IgM was 
assayed against a microarray consisting of 135 different glycan structures (Figure $\mathrm{S1}$ ), among which multiple paucimannose-type $\mathrm{N}$-glycans.

This glycan microarray has been exploited previously to quantify the immune response against S. mansoni parasitic infection (Nkurunungi et al., 2019) and therefore, the glycans included comprise structures from non-mammalian origin commonly found in invertebrates and plants with substitutions such as core $\alpha 1,3$ fucose (Fuc) and $\beta 1,2$ xylose (Xyl) (Brzezicka et al., 2015). Two-fold serial dilutions of Mannitou $\operatorname{lgM}(500,250,125$ and $62.5 \mathrm{nM})$ were incubated on the microarray at RT for one hour and interactions were revealed with Alexa Fluor 555 Goat AntiMouse IgM secondary antibody (Figure S2A). Previously, Mannitou antibody has been screened against the glycan array 4.0 of the Consortium for Functional Glycomics and demonstrated a highly restricted specificity for the $\mathrm{Man}_{3} \mathrm{GlcNAc}_{2}$ pentasaccharide (Zipser et al., 2012) and any substitution inhibited or significantly reduced binding. In line with these previous findings, our results show that Mana1-

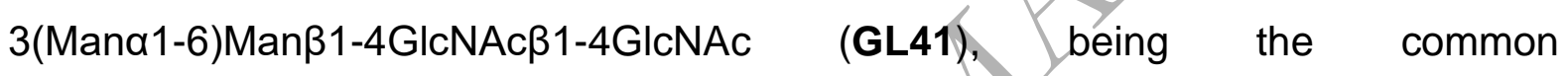
pentasaccharide core M3GN2 of all N-glycans, displays one of the highest RFU values. Nevertheless, in our experiment, Mannitou binding was not exclusive for this core structure and different printed glycans exhibited important recognition (Figures 1 and S2B).

The main conclusions drawn from the microarray screening is that the printed structures efficiently recognized by Mannitou all have in common an unsubstituted mannose (also called residue 4 in high-mannose-type oligosaccharides, lacking substitution by a1,2-linked mannoses C and D1 (Kozutsumi et al., 1986)) of the a1,3 branch in the N-glycan core. All substitutions on the a1,3 Man arm either with Mana1-2 (GL42) or with GlcNAc $\beta 1-2$ (GL55) completely abolished Mannitou IgM binding (Figure 1A). On the other hand, the substitution with core $\alpha 1,6$-fucose in Man3 N-glycan (GL70) showed similar RFU values to the non-fucosylated structure

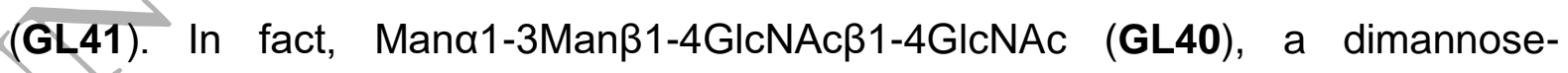
containing $N$-glycan lacking the $\alpha 1,6$ Man arm, and its $\beta 1,2$ xylosylated counterpart (GL2) were also recognized, albeit with much lower intensity than their Man3 equivalent (respectively GL41 and GL7, Figures 1A and S2). On the other hand, the sole a1-6-linked dimannose-containing structure Mana1-6(Xylß1-2)Man $\beta 1$ 4GIcNAcß1-4GIcNAc (GL1) did not bind (Figure S2), despite the absolute tolerance 
for $\beta 1,2$ xylosylation on the central mannose of the $\mathrm{N}$-glycan, thus confirming the specificity of Mannitou IgM towards the nature of the $\alpha 1,3$ glycosidic linkage.

For Mana1-3(Mana1-6)Manß1-4GlcNAcß1-4GlcNAc (GL41) and Mana1-

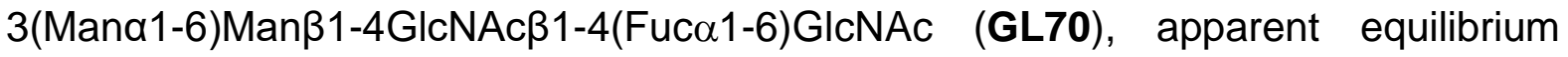
dissociation constants $\left(\mathrm{K}_{\text {dsurf }}\right)$ on the microarray surface were calculated by plotting the fluorescence intensities (relative fluorescence units, RFU) against the antibody concentrations and fitting the data to a one-site binding Langmuir isotherm (Liang et al., 2007). Both glycans showed apparent dissociation constants in the submicromolar range (Figure 1B).

The binding pattern of Mannitou IgM on the glycan microarray was compared with those of other mannose-binding lectins, namely concanavalin A (Canavalia ensiformis agglutinin, ConA) and Galanthus nivalis agglutinin (GNA) (Figure 2). A heat map allows to compare the performance of Mannitou IgM with the two lectin lectins to define the most suitable probe for applications. From all structures available in the glycan array, only paucimannose, high mannose and hybrid type structures are represented in the heat map. Although ConA, GNA and Mannitou all recognize mannose, important differences between the three proteins are highlighted (Figure 2). All recognition probes bind M3GN2 and M5GN2 N-glycan structures efficiently, but Mannitou recognized Xylß1-2-substituted M3GN2 Nglycans much more efficiently than ConA while GNA showed no binding to these structures (Brzezicka et al., 2015). Additionally, both ConA and GNA bind to several high mannose and hybrid type structures (e. g. GL65, GL54, GL45) which are not recognized by Mannitou antibody. These results highlight the importance of defining in a precise manner the binding epitopes for the different carbohydrate-binding proteins.

Based on the microarray screening results and on the reported paucimannose type structures described in pathological processes (Becker et al., 2019; Chatterjee et al., 2019), M3GN2 (GL41) and the corresponding $\alpha 1-6$ corefucosylated structure M3GN2F1(6) (GL70), were selected and synthesized chemoenzymatically (Figure S3) in sufficient amounts for subsequent Surface Plasmon 
Resonance (SPR) kinetic binding experiments and Saturation Transfer DifferenceNuclear Magnetic Resonance (STD-NMR) structural analyses.

\section{Molecular recognition studies of paucimannose $\mathrm{N}$-glycans by Mannitou IgM}

Mannitou IgM could be purified using size-exclusion chromatography due to its large molecular mass (Figure S4). The next steps involved investigating the molecular recognition of paucimannose $\mathrm{N}$-glycans by Mannitou IgM. We deciphered their specificity for Mannitou IgM by determining the kinetic parameters of binding using SPR detection (Figure 3). The synthetic M3GN2 (GL41) was immobilized on a CM5 sensor chip, as it was the minimal epitope to Mannitou IgM, and M3GN2F1(6) (GL70) on the same chip to run the microfluidics experiment under exactly the same conditions. N-glycan core a1-6-linked fucose is an important residue in carbohydrate-carbohydrate interactions, involved in complement activation and antibody-mediated cellular cytotoxicity (Ferrara et al., 2011; Sakae et al., 2017). While $\beta 1,2$-linked xylose and $\alpha 1,3$-linked fucose are immunogenic $\mathrm{N}$-glycan motifs from plants and invertebrates but absent in mammals (Brzezicka et al., 2015), in mammals core fucose is found exclusively as a1-6-linked to the reducing-end $\mathrm{N}$ acetylglucosamine (GlcNAc) moiety of the chitobiose core (Serna et al., 2011).

Mannitou IgM binds with a very fast, concentration-dependent, on-rate $\left(k_{o n}=k_{a}[C]+k_{d}\right)$ to these PMGs together with rather large dissociation rate $\left(k_{\text {off }}=k_{d}\right)$. (Table I). Such kinetics of binding are most likely helped by the dense immobilization of the glycans and re-binding effects. Indeed, only a small portion of bound IgM "sticks" and maintains a stable interaction (Figure 3). Nanomolar affinities are obtained, with no significant difference between M3GN2 and M3GN2F1(6). We next wanted to gain insight into the influence of the presentation of $P M G$ epitopes onto proteins, paucimannose-carrying proteins or PMPs.

\section{Glycoprotein differentiation by Mannitou IgM}

Mannitou IgM was allowed to interact with differently glycosylated forms of

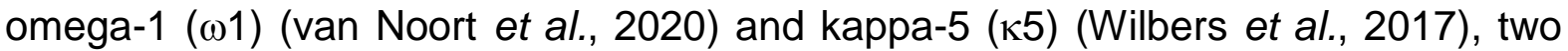
major immunomodulatory Schistosoma mansoni soluble egg antigens. Mannitou IgM 
interacted with the omega-1 glycoproteins with much lower on- rates but also smaller off-rates than for PMGs alone (Table II). This could be explained because only two glycosylation sites are present per omega-1 protein, thus the density of PMG immobilization is much lower. Another difference is that the dextran matrix was completely shielded from interaction with Mannitou IgM by the high protein immobilization rate (Figure 4). The high-mannosylated glycoform of $\kappa 5$ (Figure S5) was found not to be bound by Mannitou IgM and it was therefore used to block aspecific binding in the reference flow channel. Regeneration between the different analyte concentrations was avoided because the paucimannose-carrying glycoproteins (PMP) could be damaged using harsh eluents, instead, a single cycle kinetic titration was used. The Mannitou IgM analyte was titrated at five different concentrations, from low (59.4 nM) to high (950 nM).

Affinities $\left(\mathrm{K}_{\mathrm{d}}\right)$ fit near $100 \mathrm{nM}$, with a small favour of Mannitou IgM for $\omega 1$ M3GN2F1(6) and M5GN2 (Table II and Figure 5). For another omega-1 PMP glycanengineered with a single Le ${ }^{x}$ epitope (second $N$-glycan shown in Figure 4D) as the major glycoform (Wilbers et al., 2017), no binding was detected using SPR. In line with this observation, Le ${ }^{x}$ epitopes presented on the glycan microarray (e. g. GL91 and GL92) were not recognized by Mannitou IgM (Figure S2A). Therefore, the affinity for omega-1 presenting mixed major glycoforms of M5GN2 and Le (Figure 4D) could be most probably attributed to oligomannose-5 binding. This finding is again congruent with the results of IgM binding to M5GN2 (GL43) of the glycan microarray (Figure 1A). Possibly, the binding of M5GN2 (GL43) is a little stabilized over M3GN2 (GL41) consistently between microarray screening and SPR measurements (Table II) and judged based on the maximal binding capacity (Rmax) and affinity (Figure 5).

\section{Epitope mapping by STD-NMR spectroscopy}

STD-NMR spectroscopy is often used to determine molecular surface patches/regions on glycan epitopes that are directly involved in binding proteins such as lectins and carbohydrate-binding antibodies (Arda and Jimenez-Barbero, 2018; Henriques et al., 2020). In spectra collected in aqueous, i.e. polar, buffers, only aliphatic and aromatic epitope proton resonances are visible, while the 
polar/acidic set of $\mathrm{H}$ atoms in glycans (those that are part of hydroxyl, amine and carboxy groups) rapidly exchange with the surrounding solvent molecules (Blaum et al., 2018).

For the STD-NMR experiments, the antigen-binding fragment (Fab) of Mannitou was generated by transient transfection in mammalian $\mathrm{HEK}_{2} 23^{\top}$ cells and purified using nickel affinity chromatography (Figure S6A). A mammalian expression system was chosen because it allows an efficient post-translational processing in the secretory pathway that is vital for the correct folding of antibodies and its fragments (Aricescu et al., 2006). The bioactivity of Mannitou Fab was verified prior to STDNMR experiments by means of SPR that followed complex formation of the Fab with immobilized $\omega-1$ M3GN2 (Figure S6B). The observed fast on- and off-rates indicated it to be in the right range of affinity for STD-NMR measurements to be feasible.

${ }^{1} \mathrm{H}$-STD NMR experiments were performed using the same two PMGs selected from the microarray screening (Figure 6). The STD spectra at the aliphatic and the aromatic irradiation frequencies for the non-fucosylated M3GN2 (GL41) (Figure 6A) and fucosylated M3GN2F1(6) (GL70) (Figure 6B) were essentially the same. All protons belonging to the a1-3-linked mannose gave STD signals, where $\mathrm{H} 1$ and $\mathrm{H} 2$ were the protons with the strongest STD effect. The same protons from the mannose on the $\alpha 1,6$ arm demonstrated no STD effect. In addition, there was a very weak STD effect of $\mathrm{H} 2$ of the central $\beta M a n$ residue and a weak STD signal of the acetyl (Ac) group on the GIcNAc1 residue (Figure 6).

In the more crowded region of $3.6-3.9$ ppm, an STD effect is also observed for $\mathrm{H} 3, \mathrm{H} 4$ and $\mathrm{H} 5$ protons of the aMan residue. These protons resonate at the same frequency for $\alpha 1,6$ and $\alpha 1,3$-linked mannose, however, the above-mentioned results involving $\mathrm{H} 1$ and $\mathrm{H} 2$ suggest that they correspond to the a1,3-linked mannose. The protons of GlcNAc2 exhibited no STD effect, in contrast to the protons on the acetyl (Ac) group of the reducing end GlcNAc (GlcNAc1). This probably results from the conformation of the PMG in the protein-bound form, where the acetyl group of GlcNAc1 points to the same side as the a1,3-linked mannose, while the one of GlcNAc2 points in the opposite direction (Figure 6).

\section{A molecular model for Mannitou Fab in complex with its minimal epitope}


Molecular docking simulations indicate that the M3GN2 (GL41) PMG epitope occupies a binding site shaped by Complementary Determining Region (CDR) loops as predicted using the Paratome program (Kunik et al., 2012) on the sequence of Mannitou Fab. The amino acid sequences of the purified IgM were for the large majority covered using MALDI-TOF MS peptide fingerprinting within a $1 \%$ precision $\mathrm{m} / \mathrm{z}$ rate and confirmed the full presence of the heavy and light chains of Mannitou IgM (Figure S7). Prediction of the binding mode of M3GN2 onto the homology model of Mannitou Fab shows the a1-3-linked mannose inserted in a snug pocket on the protein surface, between Trp33 and Tyr104 respectively belonging to the heavy chain CDR1 and CDR3 (Figure 7). Running a docking simulation with the $\alpha 1-6$ corefucosylated PMG, M3GN2F1(6) (GL70), does not change this pattern of binding. However, as soon as an additional residue is substituted onto the a1-3-linked mannose, this interaction with Mannitou Fab is impeded. This is congruent with what was observed in the microarray study and is presumably due to the complementary shape of the cavity, where a substitution on the axial 2-position of the a1-3-linked mannose of M3GN2 may force it to leave its snug pocket.

\section{Discussion}

The biological importance of glycosylation in physiological and pathophysiological conditions is broadly acknowledged. Human protein paucimannosylation characterization was pioneered by the group of Nicola Parker, who discovered an unconventional form of $\alpha$ - and $\beta$-mannose epitope-rich human $N$ glycosylation, on proteins in sputum from inflamed and bacteria-infected individuals (Thaysen-Andersen et al., 2015; Venkatakrishnan et al., 2015). Namely neutrophil elastase, proteinase 3 and cathepsin $G$ had been reported earlier to be abundantly enriched in paucimannose on the plasma membrane of human neutrophils upon their activation (Campbell and Owen, 2007) and had been held responsible of driving cluster formation on the neutrophil cell surface (Hajjar et al., 2008). Mammalian PMP biogenesis has a hexosaminidase-dependent pathway, where an $\mathrm{N}$-acetyl- $\beta$-hexosaminidase trims immature complex $N$-glycans retroactively down to 
PMGs (Tjondro et al., 2019). This same strategy we have applied in the chemoenzymatic synthesis of M3GN2F (Figure S3).

Human PMG products of the hexosaminidase activity were recently characterized by quantitative proteomics (Chatterjee et al., 2019). The thus truncated $\alpha$-mannose-terminating structures spanned the monosaccharide compositions of [ $\mathrm{Man}_{1-3} \mathrm{GlcNAc}_{2} \mathrm{Fuc}_{0-1}$ ] on human paucimannose-carrying proteins (PMPs), with a prevalence of one of the two dimannose isomers, namely Mana1,6Man $\beta 1,4 \mathrm{GlcNAc} \beta 1,4$ (Fuca1,6)GlcNAcßAsn. Unsubstituted Mana1-6Man PMG was not printed on the glycan array (Figure S1) and the latter only contains the dimannose Mana1-6Man with a $\beta 1,2$-linked xylose substitution on the central $\beta$ Man (GL1) (Figure S1A). Dimannose GL1 with $\alpha 1,6$ mannose residues, but lacking $\alpha 1,3$ residues, does not show any binding to Mannitou IgM, while GL4, with a GIcNAc extension on the $\alpha 1,6$ Man arm is tolerated and demonstrate's binding to Mannitou (Figure S2). The binding of the GL1 glycan can be directly compared with the Mana1-3Man dimannose equivalent, GL2. GL2, GL8 and GL40 are all Mana1-3Man dimannose PMGs with similar weak binding signals, whereas the M3GN2 structures GL7 and GL41 showed strong binding to Mannitou IgM, independent of the presence of $\beta 1,2$-linked xylose on the central mannose. For all these reasons, the absence of signal for the $\alpha 1-6$-linked dimannose PMG (GL1) was interpreted to be due to non-binding of the $\alpha 1,6$-arm and this $\mathrm{N}$-glycan was not included in subsequent analyses. Among other PMGs found in human paucimannosylation, M1GN2 (GL39) displaying a single mannose residue, did also not bind Mannitou IgM (Figure S2A).

Mannitou only displays significant affinities from oligomannose-3 on, represented by the minimal epitope M3GN2. Measured affinities are near $100 \mathrm{nM}$ ( $\left(\mathrm{K}_{\mathrm{d}}\right)$ both in glycan array and SPR experiments (Figure 1B and Table II). ${ }^{1} \mathrm{H}$-STD NMR experiments were performed using two PMGs selected from the microarray screening. Non-fucosylated M3GN2 (GL41) (Figure 6A) and fucosylated M3GN2F1(6) (GL70) (Figure 6B), PMG epitopes for Mannitou Fab, displayed very similar STDDD spectra in which the same protons showed analogous ${ }^{1} \mathrm{H}$-STD NMR effects. The two epitopes are thus estimated the same. What is more, the intensities 
of their STD signals were the same, which indicates that their interactions are also the same in terms of affinity. Likewise, when printed on the microarray (Figure 1), immobilized on the SPR sensor chip (Table I) or presented on one of the omega-1 glycosylation sites (Table II), there appears no significant difference in affinity between the two PMGs (Figure 5). That suggests that no hindrance, nor significant contribution to affinity, is made by the fucose $\alpha 1,6$-linked to the core GlcNAc1 (Figure 6). It has been described that core fucose may lead to a different) presentation of the $\mathrm{N}$-glycan and introduce dynamics in the glycan chain (Sakae et al., 2017). Yet, the presence of the $\alpha 1-6$-linked core fucose does not hinder binding to Mannitou, which is a positive point for the use of the antibody in diagnosis of PMGs and PMPs, as M3GN2 and M3GN2F1(6) were both found to be very important PMGs in human cancer samples (Chatterjee et al., 2019).

STD-NMR spectroscopy revealed that the protons strongest implicated in interactions with Mannitou were $\mathrm{H} 1$ and $\mathrm{H} 2$ on the a1,3-linked mannose, with weaker signals from the other protons of the same arm, from the $\mathrm{H} 2$ proton of the central BMan and from the acetyl group of GlcNAc1 at the reducing end of the $\mathrm{N}$ glycan (Figure 6). Interestingly, the STDDD spectra at the aliphatic and the aromatic irradiation frequencies were essentially identical. Coherent with the ${ }^{1} \mathrm{H}-\mathrm{STD}$ NMR measurements, molecular simulations indicate that Mana1-3 might dock into a pocket, or hydrophobic groove, formed by aromatic residues of the predicted CDR loops of the Mannitou Fab (Figure 7). These conclusions are fully in line with the results from the microarray and from the docking, which showed that any substitution at the 2-position of $\alpha$ Man on the $\alpha 1,3$ Man arm, either with Mana1-2 (GL42) or with GlcNAcß1-2 (GL55), abolishes binding (Figure 1A). Once the requirement of the unsubstituted $\alpha 1,3$ Man arm is fulfilled, the substitution of the $\alpha 1,6$ Man arm showed an important permissiveness in the structure (GL23, GL27, GL34, Figure S2). Additionally, different non-mammalian substitutions such as core Xy) 1 1-2 (G2, G7, Figure S2), core Fuca1-3 (G72, G90, Figure S2) and core-bis fucosylation (GL10, GL75, Figure S2) did not impede binding. As these structures are not part of the mammalian glycome, they were not considered for further studies, but this data could open new applications of Mannitou antibody in invertebrate and parasitic glycomic studies. 
Among the high-mannose structures printed, only Man5 $\mathrm{N}$-glycan (GL43, Figure 1A) and core fucose substituted Man5 N-glycans (GL74, GL134 in Figure S2B) were recognized by the antibody efficiently. Considering these results, there is a quantitative difference in recognition between our screening and previously published data (Zipser et al., 2012), where on the glycan array from the Consortium for Functional Glycomics a small fluorescence signal was detected for pentamannose (Man5, without the chitobiose core) and only a very minor fluorescence signal for M5GN2. The Man5 N-glycan M5GN2 (GL43) was therefore previously described to have only a residual binding towards Mannitou antibody, while in our data it was recognized at least as efficiently as M3GN2 (GL41). For the same PMGs presented on a glycoprotein, omega-1 M5GN2 \& L $\mathrm{e}^{\mathrm{x}}$, a similar affinity was observed as for omega-1 M3GN2 (Table II, Figure 5). Glycan densities may play an important role in the binding of the multivalent $\operatorname{lgM}$, and we also observed this effect using SPR in a significantly higher affinity for PMGs, that were much more densely immobilized, than for PMP binding (Figure 5). It is perhaps not so surprising for carbohydrate-binding proteins specific for the $\alpha 1,3 \mathrm{Man}$ arm of the $\mathrm{N}$-glycan core structure to have a tolerance for substitutions on the $\alpha 1,6$ Man arm. It is not unusual either, for instance a similar non-distinction between M3GN2 and M5GN2 has been found for the FimH lectin from Escherichia coli (Bouckaert et al., 2006). In contrast, the kappa-5 glycoprotein carrying predominantly M7GN2 and M8GN2 (Figure S5) did not bind Mannitou IgM and for this reason it was used as the baseline reference in the SPR experiments (Figure 4). In conclusion, our results indicate that Mannitou antibody has submicromolar affinities also for oligomannose-5 N-glycans, that are generally not called paucimannosidic.

Alpha-mannose determinants are relative rare glycan-epitopes in physiological extracellular environments (Dahmen et al., 2015), but may be actively secreted or leaked from cells to transmit potent signals when required (ThaysenAndersen et al., 2015; Loke et al., 2017). Our understanding of the role of these signals in mounting an effective immune response during physiological and pathophysiological conditions is rapidly advancing. The functional implications of Mannitou IgM binding M3GN2 and M5GN2 epitopes will likewise need to be further 
addressed. In conclusion, our multidisciplinary approach of the molecular recognition of paucimannose $\mathrm{N}$-glycans by Mannitou antibody by glycan microarrays, SPR, STD-NMR, modelling and docking allowed to pinpoint the minimal epitopedetermining regions of the glycan and shed light on the paratope of Mannitou. Our study highlights the rational for the "forbidden" substitution on the $\alpha 1,3$-linked mannose branch of the N-glycan pentasaccharide core Man3GlcNAc2. Gaining a better structural insight into the selectivity of the monoclonal antibody warrants to improve its diagnostic qualities in specifically targeting distinct types of paucimannosylation.

\section{Materials and Methods}

\section{Gene sequencing of Mannitou IgM}

The genomic sequences of the variable domains ( $\mathrm{V} Y$ and $\mathrm{VH}$ ) of Mannitou antibody were determined by Fusion Antibodies Ltd (Belfast, Northern Ireland) by mRNA extraction from hybridoma cells (Laz6-189/Mannitou mAb available from the DSHB, deposited by B. Zipser) and CDNA synthesis by RT-PCR. The positive PCR products were identified by agarose gel electrophoresis and sequenced on an ABI3130xI Genetic Analyzer (Applied Biosystems).

\section{Mannitou IgM expression, purification and variable region sequence analysis}

In order to produce Mannitou IgM, hybridoma cells were cultured in serumfree medium (SFM) for three weeks and allow to secrete mAb in the medium. Subsequently, the supernatant was recovered and the Mannitou IgM was purified using a HiLoad ${ }^{\mathrm{TM}} 16-600$ Superose $^{\mathrm{TM}} 6$ prep grade size exclusion chromatography column on an ÄKTA Pure (Cytiva). The running buffer consisted of $0.2 \mathrm{M}$ sodium bicarbonate at $\mathrm{pH}=8$ and $0.5 \mathrm{M} \mathrm{NaCl}$. The separation was carried out at a maximum flow rate of $0.5 \mathrm{ml} / \mathrm{min}$.

Peptide mass fingerprinting using MALDI-TOF was performed upon in-gel digestion of Mannitou IgM using trypsin. The protein bands for heavy and light chain were excised and subjected to an in-gel digestion protocol consisting of dithiothreitol reduction at $56^{\circ} \mathrm{C}(10 \mathrm{mM}, 20 \mathrm{~min})$, followed by iodoacetamide alkylation $(55 \mathrm{mM}, 20$ min in a dark environment) and finally trypsin incubation $(12.5 \mu \mathrm{g} / \mu \mathrm{L})$ overnight at 
$37^{\circ} \mathrm{C}$. After digestion, peptides were extracted with ammonium bicarbonate $(25 \mathrm{mM})$ and trifluoroacetic acid $(0.1 \%$ in water). The sequences for the variable domains were uploaded in the data base together with the constant regions (UniProtKB P01872 or entry IGHM_MOUSE for the heavy constant $\mu$ chain, P01837 or entry IGKC_MOUSE for the light $\mathrm{K}$ constant domain) to enable proteomics analysis of the peptide mass fingerprinting MALDI-TOF spectrometric data. The Complementarity Determining Regions or CDRs were predicted using the program Paratome (KuniK et) al., 2012) and glycosylation was predicted based on programs NetNGlyc (Gupta and Brunak, 2002) and NetOGlyc (Steentoft et al., 2013).

\section{Microarray preparation and screening with Mannitou IgM and plant lectins}

The glycan microarrays were prepared as described earlier (Brzezicka et al., 2015). Briefly, $50 \mu \mathrm{M}$ ligand solutions ( $1.25 \mathrm{~nL}, 5$ drops, $250 \mathrm{pL}$ drop volume) in sodium phosphate buffer (300 mM, 0.005\% Tween-20, $\mathrm{pH}=8.4$ ) were spatially arrayed employing a robotic non-contact piezoelectric spotter (SciFLEXARRAYER S11, Scienion) onto $N$-hydroxysuccinimide (NHS) activated glass slides (Nexterion $H$, Schott $A G)$. After printing, the slides were placed in a $75 \%$ humidity chamber for 18 hours at $25^{\circ} \mathrm{C}$. The remaining NHS groups were quenched with $50 \mathrm{mM}$ solution of ethanolamine in sodium borate buffer $(50 \mathrm{mM}, \mathrm{pH}=9.0)$ for $1 \mathrm{~h}$. The slides were washed with PBST (PBS/0.05\% Tween-20), PBS and water, then dried in a slide spinner and stored at $-20^{\circ} \mathrm{C}$ until use. Mannitou monoclonal antibody, secreted by the hybridoma cells in the serum-free medium, was diluted to approximately 25 $\mu \mathrm{g} / \mathrm{mL}$ in PBS (1\% BSA, 0.01\% Tween-20). The antibody solution $(200 \mu \mathrm{L})$ was incubated on the microarrays for $1 \mathrm{~h}$ at RT. The slides were washed with PBST and PBS. Next, they were incubated with Alexa Fluor 555 Goat Anti-Mouse IgM (1:1000) (Thermo Fischer Scientific) in PBS (1\% BSA, 0.01\% Tween-20) for $1 \mathrm{~h}$ in the dark. The microarrays were washed from the unbound secondary antibody with PBST, PBS and water. Solutions of fluorescently labelled ConA-555 $(10 \mu \mathrm{g} / \mathrm{mL})$ and GNA$555(25 \mathrm{\mu g} / \mathrm{mL}$ ) in TSM buffer (Tris $25 \mathrm{mM}, 150 \mathrm{mM} \mathrm{NaCl}, \mathrm{pH}=7.5)$ containing $2 \mathrm{mM}$ $\mathrm{CaCl}_{2}$ and $2 \mathrm{mM} \mathrm{MgCl}_{2}$ were incubated in the glycan microarray at $\mathrm{RT}$ for 1 hour in the dark. The slides were washed with TSM buffer containing $0.01 \%$ Tween-20 and water. Slides were subsequently dried in a slide spinner dried. The fluorescence measurements were performed on Agilent G2565BA Microarray Scanner (Agilent Technologies) at $10 \mu \mathrm{m}$ resolution. The quantification of fluorescence was done 
using ProScanArray Express software (Perkin Elmer) employing an adaptive circle quantification method from $50 \mu \mathrm{m}$ (minimum spot diameter) to $300 \mu \mathrm{m}$ (maximum spot diameter). Average RFU (Relative Fluorescence Unit) values with local background subtraction of four spots and standard deviation of the mean were reported using Microsoft Excel and GraphPad Prism software.

\section{Synthesis of M3GN2 and M3GN2F1(6) paucimannosidic glycans}

M3GN2 (GL41) and M3GN2F1(6) (GL70), each figuring an amino-pentyl spacer at their reducing end (Figure S3), were prepared using a modular synthesis starting from biantennary G0, as described earlier (Serna et al., 2010). Core ( $(\alpha 1-6)$ fucosylation on G0 (5.2 mg, $3.68 \mu \mathrm{mol})$ was effected using the GDP-fucose (3.3 mg, $5.52 \mu \mathrm{mol}$ ) donor and the Anopheles gambiae FUT6 enzyme (Serna et al., 2013) in MES buffer ( $80 \mathrm{mM}, \mathrm{pH}=6.5)$ including $\mathrm{MnCl}_{2}(20 \mathrm{mM})$, by stirring at RT until complete consumption of the starting material. Next, core $(\alpha 1-6)$ fucosylated G0 was treated with $\beta$ - $N$-acetylglucosaminidase from Streptococcus pneumoniae (New England Biolabs) in sodium acetate buffer ( $50 \mathrm{mM}, \mathrm{pH}=5.5)$ including $\mathrm{CaCl}_{2}(5 \mathrm{mM})$ at $37^{\circ} \mathrm{C}$ until complete consumption of the starting material. The crude product was purified on Bond Elute carbon graphitized cartridges (Agilent) to yield $2.0 \mathrm{mg}$ Man3GlcNAc(Fuca1-6)GlcNAc (1.76 $\mu \mathrm{mol}$ ) or a 48\% yield over the two steps (Figure S3): ${ }^{1} \mathrm{H}$ NMR $\left(500 \mathrm{MHz}, \mathrm{D}_{2} \mathrm{O}\right) \delta 5.12(\mathrm{~d}, J=1.7 \mathrm{~Hz}, 1 \mathrm{H}), 4.93(\mathrm{~d}, J=1.6 \mathrm{~Hz}, 1 \mathrm{H})$, $4.91(\mathrm{~d}, J=4.0 \mathrm{~Hz}, 1 \mathrm{H}), 4.68(\mathrm{~d}, J=7.9 \mathrm{~Hz}, 1 \mathrm{H}), 4.51(\mathrm{~d}, J=8.1 \mathrm{~Hz}, 1 \mathrm{H}), 4.27(\mathrm{~d}, J$ $=1.9 \mathrm{~Hz}, 1 \mathrm{H}), 4.14(\mathrm{q}, J=6.8 \mathrm{~Hz}, 1 \mathrm{H}), 4.08(\mathrm{dd}, J=3.4,1.5 \mathrm{~Hz}, 1 \mathrm{H}), 3.98(\mathrm{dd}, J=$ 3.4, $1.7 \mathrm{~Hz}, 1 \mathrm{H}), 3.97-3.56(\mathrm{~m}, 30 \mathrm{H}), 3.05-2.94(\mathrm{~m}, 2 \mathrm{H}), 2.11(\mathrm{~s}, 3 \mathrm{H}), 2.04(\mathrm{~s}$, $3 \mathrm{H}), 1.73-1.55(\mathrm{~m}, 4 \mathrm{H}), 1.47-1.35(\mathrm{~m}, 2 \mathrm{H}), 1.24(\mathrm{~d}, J=6.6 \mathrm{~Hz}, 3 \mathrm{H})$. The HRMS (MALDI-TOF) m/z [M+Na] calculated for $\mathrm{C}_{45} \mathrm{H}_{79} \mathrm{~N}_{3} \mathrm{NaO}_{30}$ 1164.4646, was found to be 1164.4664.

\section{PMG - Mannitou IgM kinetics of binding detected using SPR}

The chip for the multi-cycle analysis using Mannitou IgM was prepared by direct immobilization of $\mathrm{Man}_{3} \mathrm{GlCNAc}_{2}$ (GL41) and Man ${ }_{3}$ GlcNAcFuc1 (GL70). Man ${ }_{3} \mathrm{GlCNAc}_{2}$ was covalently immobilized via amine coupling at $237 \mathrm{RU}\left(237 \mathrm{pg}\right.$ ligand $/ \mathrm{mm}^{2}$ sensor surface) in Fc2 and $\mathrm{Man}_{3} \mathrm{GlcNAc}_{2} \mathrm{Fuc1}$ at $163 \mathrm{RU}$ in Fc4 on a CM5 sensor chip using $10 \mathrm{mM} \mathrm{NaAc}$ at $\mathrm{pH}=4.5$ as immobilization buffer. $\mathrm{Fc}_{\mathrm{c} 1}$ and $\mathrm{Fc} 3$ were blocked immediately after activation and served as reference surfaces. The binding 
interaction was studied using increasing concentrations of Mannitou mAb (0 nM, 0.8 $\mathrm{nM}, 0.16 \mathrm{nM}, 0.33 \mathrm{nM}, 0.66 \mathrm{nM}, 1.31 \mathrm{nM}, 2.63 \mathrm{nM}, 5.25 \mathrm{nM}, 10.5 \mathrm{nM}, 21 \mathrm{nM}, 42$ $\mathrm{nM}, 84 \mathrm{nM}, 168 \mathrm{nM}, 336 \mathrm{nM}$ ) in $200 \mathrm{mM} \mathrm{NaHCO}_{3}, 500 \mathrm{mM} \mathrm{NaCl}, \mathrm{pH}=7.8$ buffer, at a flow rate of $30 \mu \mathrm{l} / \mathrm{min}$ at $10^{\circ} \mathrm{C}$. Each sample injection ( $1 \mathrm{~min}$ contact time, $6.5 \mathrm{~min}$ dissociation time) was followed by a regeneration using with $50 \mathrm{mM} \mathrm{NaOH}$.

\section{PMP - Mannitou interactions and affinities using SPR detection}

Glyco-engineered omega-1 ( $\omega 1$, UniProt Q2Y2H4) helminth glycoproteins were plant-produced in Nicotiana benthamiana and purified using cation exchange chromatography, as described previously (Wilbers et al., 2017). The sensor chip for single-cycle analysis using Mannitou IgM was prepared by immobilizing $\triangle \mathrm{XT} / \mathrm{FT} \omega 1$ carrying predominantly the carrying the $N$-glycan of choice. $10 \mu \mathrm{g} / \mathrm{ml}$ of glycoprotein was covalently immobilized via amine coupling in $10 \mathrm{mM} \mathrm{NaOOCCH} 3$ at $\mathrm{pH}=4.5$. M3GN2 was immobilized at $2300 \mathrm{RU}$ (2300 pg PMG/mm ${ }^{2}$ sensor surface) in Fc2, 11 M3GN2F1(6) at $2000 \mathrm{RU}$ in Fc3, and $\omega 1$ M3GN2F1(3) at $2500 \mathrm{RU}$ in Fc4. For these PMPs, MALDI-TOF glycosylation profiles are available respectively from Figures 2D, $2 \mathrm{E}$ and $2 \mathrm{G}$ in a recent publication (van Noort et al., 2020). The other tested omega-1 glycoproteins $\omega 1$ M5GN2 \& Le $e^{x}$ and 01 single $L^{x}$ were immobilized at 3270.6 and $2604.8 \mathrm{RU}$, respectively. The $\omega 1 \mathrm{M} 6 \mathrm{GN} 2 \& \mathrm{Le}^{\mathrm{x}}$ protein carries a mixture of oligomannose-5 (GL43 counterpart) and Le ${ }^{\mathrm{x}}$ (GL91 counterpart) N-glycans upon coexpression of $d 35 S$ :sialFucT and $d 35 S$ :sialGalT transferases, whereas the $\omega 1$ single $\mathrm{Le}^{\mathrm{x}}$ protein was expressed using a weaker, constitutive, Gpa2 promoter to reduce sialGalT expression, resulting in an almost complete lack of hybrid Le $\mathrm{e}^{\mathrm{x}}$-type $\mathrm{N}$ glycans and enabling the synthesis of relatively homogeneous $\mathrm{N}$-glycans carrying a single Le ${ }^{x}$ motif (GL91 counterpart). The MALDI-TOF glycosylation profiles are available from respectively Figures 3A and 3C, in (Wilbers et al., 2017). Engineered kappa-5 ( $\kappa 5$ ) is another glycoprotein from S. mansoni (Wilbers et al., 2017) that displays high-mannose $\mathrm{N}$-glycans (M7GN2/M8GN2) larger than oligomannose-5 (Figure S5), produced using kappa-5 (strain AGL) + P19 (strain AGL) with coexpression of the SmFucTD and pHYG-GPAll-DrGalT transferases (van Noort et al., 2020). Since no Mannitou IgM binding could be detected to the engineered kappa-5, even upon an immobilization rate of $3000 \mathrm{RU}$, this protein served as a blank. It was covalently immobilized in the reference flow channel Fc1 in order to block the sensor 
surface from a-specific binding and prepare Fc2-Fc1, Fc3-Fc1 and Fc4-Fc1 difference sensorgrams. The binding was studied using increasing concentrations of Mannitou IgM (59.375 nM, 118.75 nM, 237.5 nM, 475 nM, 950 nM) in $200 \mathrm{mM}$ $\mathrm{NaHCO}_{3}, 500 \mathrm{mM} \mathrm{NaCl}, \mathrm{pH}=7.8$ buffer, at a flow rate of $30 \mu \mathrm{l} / \mathrm{min}$ at $10^{\circ} \mathrm{C}$. Each sample injection ( $3 \mathrm{~min}$. association) was followed by $4 \mathrm{~min}$. dissociation. All SPR data analysis was performed with BIA Evaluation Software.

\section{Mannitou Fab expression and purification}

CDNA fragments encoding the light chain (LC), and the heavy-chain variable domain $(\mathrm{VH})$ with the first domain of the heavy-chain constant region, referred to as $\mathrm{HC}$, were codon-optimized, synthesized and subcloned into a pUC57 E. coli expression vector (GenScript). The DNA of interest was amplified by PCR using primers HC_FP: GACTAGTACCGGTGAGGTGAAGCTTCTCGAGTCTGG, HC_RP: GACTAGTGGTACCTTAGTGATGGTGATGG,

LC_FP: GACTAGTACCGGTGATGTTGTGGTGACTCAAACTCCACTC and LC_RP: GACTAGTGGTACCTTAACACTCTTTCCTGTTG (FP is forward primer and RP is reverse primer). The PCR products were digested with Agel and Kpnl restriction enzymes, purified, and ligated into $\mathrm{pH}$ L-sec expression vectors. The $\mathrm{HC}$ insert was cloned between a secretion signal sequence and in frame with a $C$-terminal 6histidine tag, whereas the LC fragment carried a stop codon before the Kpnl cleavage site (Aricescu et al., 2006). The expression of Mannitou Fab was achieved by transient transfection of adherent human embryonic kidney (HEK293T) cells, cultured in high-glucose DMEM (Dulbecco's Modified Eagle's Medium) supplemented with L-glutamine, non-essential amino acids and $2 \%$ FBS (Thermo Fisher Scientific). Equal amounts of plasmid DNA encoding the heavy and light chains were used for transfection - $1 \mu \mathrm{g}$ of each vector per $1 \mathrm{ml}$ of transfection volume. The DNA-PEI MAX (Transfection Grade Linear Polyethylenimine Hydrochloride, $\mathrm{MW}=40,000 \mathrm{Da}$ ) solution (1:2) was incubated for $10 \mathrm{~min}$ at RT to allow the complex formation prior transfection. The cells were grown in expandedsurface polystyrene roller bottles $\left(2125 \mathrm{~cm}^{2}\right.$, CELLMASTER, Greiner Bio-One) at 37 ${ }^{\circ} \mathrm{C}$, in a humidified atmosphere of $5 \% \mathrm{CO}_{2}$ in air, inside a roller bottle incubator. The cell-culture supernatant was harvested 7 days post-transfection, clarified by centrifugation at $6000 \times g$ for $20 \mathrm{~min}$, then filtered through a $0.45 \mu \mathrm{m}$ membrane and diluted threefold with PBS. The Fab was by affinity chromatography using $\mathrm{Ni}$ - 
Sepharose 6 Fast Flow resin (Cytiva) exploiting the selective His 6 -tag at the $C$ terminus of the $\mathrm{Fab} \mathrm{HC}$. The binding buffer consisted of $50 \mathrm{mM} \mathrm{NaH}_{2} \mathrm{PO}_{4}$ at $\mathrm{pH}=8.0$ and $300 \mathrm{mM} \mathrm{NaCl}$. Two consecutive washes with ascending concentrations of imidazole $(10 \mathrm{mM}$ and $30 \mathrm{mM}, \mathrm{pH}=7.0)$ were performed to eliminate as many impurities as possible. Mannitou Fab was eluted with $250 \mathrm{mM}$ imidazole in a buffer of $50 \mathrm{mM} \mathrm{NaH}_{2} \mathrm{PO}_{4}$ at $\mathrm{pH}=7.0$ and $300 \mathrm{mM} \mathrm{NaCl}$. The antibody was further purified by size-exclusion chromatography on a Superose 6 Increase 10/300 GL column (Cytiva) using buffer consisting of $20 \mathrm{mM}$ 4-(2-hydroxyethyl)-1piperazineethanesulfonic acid (HEPES) at $\mathrm{pH}=7.4$ and $150 \mathrm{mM} \mathrm{NaCl}$.

\section{Epitope mapping in STD-NMR Spectroscopy}

${ }^{1} \mathrm{H}$-STD NMR experiments were performed at $25^{\circ} \mathrm{C}$ on a Bruker AVANCE III $800 \mathrm{MHz}$ spectrometer equipped with a cryoprobe. Samples were prepared in PBS buffer in $\mathrm{D}_{2} \mathrm{O}(\mathrm{pD}=7.4)$ in $3 \mathrm{~mm}$ NMR tubes. The measurements were taken using a 40:1 molar ratio with a $1 \mathrm{mM}$ concentration of the oligosaccharide epitope and a 25 $\mu \mathrm{M}$ concentration of Mannitou Fab. Chemical shifts for the epitope were recorded at one off-resonance (no signals of protein or ligand) irradiation frequency set at 100 ppm and two on-resonance irradiation frequencies, one set on the aliphatic region of the protein signals $(0.8 \mathrm{ppm})$ and one set on the aromatic region of the protein signals (6.9 ppm). Protein saturation was achieved with a train of Gaussian-shaped pulses of 50 ms duration, with a total irradiation time of 2 s. STD spectra were obtained by subtracting the on-resonance from the off-resonance (reference) spectrum. Subtraction of ${ }^{1} \mathrm{H}$-STD NMR spectra of the free ligands at $1 \mathrm{~mm}$ in $\mathrm{D}_{2} \mathrm{O}$ was also acquired to ensure that no direct irradiation of the oligosaccharide was taking place. Finally, because some signals were present in STD spectra from the antibody, that interfere in the analysis of the epitope protons, a second STD experiment was acquired on a sample of the protein alone. This spectrum serves as a blank that can be subtracted from the STDD spectra in the presence of the oligosaccharide epitope to obtain the final, cleaner STDDD spectra. Data acquisition and processing were performed with TopSpin 3.0 software (Bruker) and the figures were built using MestReNova v.8.0.2.

\section{Homology modelling and molecular docking}


A model of Mannitou Fab was obtained using homology modelling by supplying the crystal structures of the heavy chain of human monoclonal antibody CR4354 (1.4 Å, PDB ID: 3N9G, sequence identity: 31\%) and the light chain of IGG1K B13I2 (2.8 Å, PDB ID: 1IGF, sequence identity: $79 \%$ to the program Modeller (Sali and Blundell, 1993). Subsequently, energy minimization of the global model was done applying AMBER forcefield in order to remove putative steric clashes between the side chains. Simulation of possible binding modes of the studied paucimannosidic $\mathrm{N}$-glycans to this three-dimensional model of Mannitou Fab was performed using GOLD docking program (Jones et al., 1997). GOLD is based on a genetic algorithm and, in this case, considers the ligands as highly flexible as they are glycosidic compounds, while the side chains of most of the residues are kept rigid. For the search procedure, a sphere of $10 \AA$ was centered on the CDRs of the variable region of the Fab. The different binding poses were scored with the ChemPLP scoring function and the pose with the best ChemPLP docking score was presented on the molecular surface of the Mannitou Fab homology model for further structural analysis.

\section{Funding}

This work was performed with financial support from the European commission, H2020-MSCA-ITN grant 675671 to J. Bouckaert and J. Jiménez-Barbero, the Centre National de la Recherche Scientifique (CNRS) and the Ministère de l'Enseignement Supérieur et de la Recherche in France. We are grateful to our colleagues involved in the European Training Network GlycoVax, for communications and training to early-stage researcher S. Robakiewicz. C. Bridot was supported by the National Agency for Research (ANR project HICARE 17CE07-028-01), S. Semwal by 847568 - PEARL - H2020-MSCA-COFUND-2018 granted to the foundation I-Site ULNE. N.G.A. Abrescia was supported by grant RTI2018-095700-B-I00 from the Spanish Ministerio de Ciencia, Innovacion y Universidades. MICINN is also thanked for the Severo Ochoa Excellence Accreditation to the CIC bioGUNE (SEV-2016-0644). S. N. Savvides is supported in part by grants from the FWO to K.V. (1524918N), a Concerted Research Action grant from Ghent University to S.N.S. (BOF17-GOA- 
028), a Hercules Foundation infrastructure grant (AUGE-11-029), and a programme grant from the VIB.

\section{Acknowledgements}

We are grateful to Cornelis $\mathrm{H}$. Hokke and Linh Nguyen from Leiden University Medical Center, The Netherlands, for N-glycan structural analysis of kappa-5. We would like to give special thanks to Brigitte Schmidt, Simone Diestel and Birgit Zipser for sharing the hybridoma cell line Laz6-189.

\section{References}

Aebi M, Bernasconi R, Clerc S, Molinari M. 2010. N-glycan structures: recognition and processing in the ER. Trends Biochem.Sci. 35, 74-82.

Arda A, Jimenez-Barbero J. 2018. The recognition of glycans by protein receptors. Insights from NMR spectroscopy. Chem Commun (Camb) 54, 4761-4769.

Aricescu AR, Lu W, Jones EY. 2006. A time- and cost-efficient system for high-level protein production in mammalian cells. Acta Crystallogr., Sect.D: Biol.Crystallogr. 62, 1243-1250.

Bajt ML, Schmitz B, Schachner M, Zipser B. 1990. Carbohydrate epitopes involved in neural cell recognition are conserved between vertebrates and leech. $J$ Neurosci Res 27, 276-285.

Becker Y, Forster S, Gielen GH, Loke 1 , Thaysen-Andersen M, Laurini C, Wehrand K, Pietsch T, Diestel S. 2019. Paucimannosidic glycoepitopes inhibit tumorigenic processes in glioblastoma multiforme. Oncotarget 10, 4449-4465.

Blaum BS, Neu U, Peters T, Stehle T. 2018. Spin ballet for sweet encounters: saturation-transfer difference NMR and X-ray crystallography complement each other in the elucidation of protein-glycan interactions. Acta Crystallogr $F$ Struct Biol Commun 74, 451-462.

Bouckaert J, Mackenzie J, de Paz JL, Chipwaza B, Choudhury D, Zavialov A, Mannerstedt K, Anderson J, Pierard D, Wyns L et al. 2006. The affinity of the FimH fimbrial adhesin is receptor-driven and quasi-independent of Escherichia coli pathotypes. Molecular Microbiology 61, 1556-1568.

Bruxelle JF, Kirilenko T, Qureshi Q, Lu N, Trattnig N, Kosma P, Pantophlet R. 2020. Serum alpha-mannosidase as an additional barrier to eliciting oligomannosespecific HIV-1-neutralizing antibodies. Sci Rep 10, 7582.

Brzezicka K, Echeverria B, Serna S, van Diepen A, Hokke CH, Reichardt NC. 2015. Synthesis and microarray-assisted binding studies of core xylose and fucose containing N-glycans. ACS Chem Biol 10, 1290-1302.

Campbell EJ, Owen CA. 2007. The sulfate groups of chondroitin sulfate- and heparan sulfate-containing proteoglycans in neutrophil plasma membranes are novel binding sites for human leukocyte elastase and cathepsin G. J Biol Chem 282, 14645-14654.

Chatterjee S, Lee LY, Kawahara R, Abrahams JL, Adamczyk B, Anugraham M, Ashwood C, Sumer-Bayraktar Z, Briggs MT, Chik JHL et al. 2019. Protein Paucimannosylation is an Enriched N-glycosylation Signature of Human Cancers. Proteomics 10.1002/pmic.201900010, e1900010. 
Dahmen AC, Fergen MT, Laurini C, Schmitz B, Loke I, Thaysen-Andersen M, Diestel S. 2015. Paucimannosidic glycoepitopes are functionally involved in proliferation of neural progenitor cells in the subventricular zone. Glycobiology 25, 869-880.

de Vroome SW, Holst S, Girondo MR, van der Burgt YEM, Mesker WE, Tollenaar R, Wuhrer M. 2018. Serum N-glycome alterations in colorectal cancer associate with survival. Oncotarget 9, 30610-30623.

Ferrara C, Grau S, Jager C, Sondermann P, Brunker P, Waldhauer I, Hennig M, Ruf A, Rufer AC, Stihle $M$ et al. 2011. Unique carbohydrate-carbohydrate interactions are required for high affinity binding between FcgammaRIII and antibodies lacking core fucose. Proceedings of the National Academy of Sciences of the United States of America 108, 12669-12674.

Flaster MS, Schley C, Zipser B. 1983. Generating monoclonal antibodies against excised gel bands to correlate immunocytochemical and biochemical data. Brain Res 277, 196-199.

Gupta R, Brunak S. 2002. Prediction of glycosylation across the human proteome and the correlation to protein function. Pac Symp Biocomput, 310-322.

Hajjar E, Mihajlovic M, Witko-Sarsat V, Lazaridis T, Reuter N. 2008. Computational prediction of the binding site of proteinase 3 to the plasma membrane. Proteins 71, 1655-1669.

Henriques P, Dello lacono L, Gimeno A, Biolchi A, Romano MR, Arda A, Bernardes GJL, Jimenez-Barbero J, Berti F, Rappuoli R et al. 2020. Structure of a protective epitope reveals the importance of acetylation of Neisseria meningitidis serogroup A capsular polysaccharide. Proceedings of the National Academy of Sciences of the United States of America 117, 2979529802.

Houdou M, Foulquier F. 2020. [Panorama on congenital disorders of glycosylation (CDG): from 1980 to 2020]. Med Sci (Paris) 36, 735-746.

Jones G, Willett P, Glen RC, Leach AR, Taylor R. 1997. Development and validation of a genetic algorithm for flexible docking. J Mol Biol 267, 727-748.

Kozutsumi Y, Nakao Y, Teramura T, Kawasaki T, Yamashina I, Mutsaers JH, van Halbeek H, Vliegenthart JF. 1986. Structures of oligomannoside chains of alpha-mannosidase from porcine kidney. J Biochem 99, 1253-1265.

Kunik V, Ashkenazi S, Ofran Y. 2012. Paratome: an online tool for systematic identification of antigen-binding regions in antibodies based on sequence or structure. Nucleic Acids Res 40, W521-524.

Lau KS, Partridge EA, Grigorian A, Silvescu CI, Reinhold VN, Demetriou M, Dennis JW. 2007. Complex N-glycan number and degree of branching cooperate to regulate cell proliferation and differentiation. Cell 129, 123-134.

Lau KS, Dennis JW. 2008. N-Glycans in cancer progression. Glycobiology 18, 750760.

Lauc G, Rudan I, Campbell H, Rudd PM. 2010. Complex genetic regulation of protein glycosylation. Mol.Biosyst. 6, 329-335.

Liang P-H, Wang S-K, Wong C-H. 2007. Quantification of carbohydrate-protein interactions using glycan microarrays: determination of surface and solution dissociation constants. J Am Chem Soc 129, 11177-11184.

Lin Al, Philipsberg GA, Haltiwanger RS. 1994. Core fucosylation of high-mannosetype oligosaccharides in GlcNAc transferase I-deficient (Lec1) $\mathrm{CHO}$ cells. Glycobiology 4, 895-901. 
Loke I, Kolarich D, Packer NH, Thaysen-Andersen M. 2016. Emerging roles of protein mannosylation in inflammation and infection. Mol Aspects Med 51, 3155.

Loke I, Ostergaard O, Heegaard NHH, Packer NH, Thaysen-Andersen M. 2017. Paucimannose-Rich N-glycosylation of Spatiotemporally Regulated Human Neutrophil Elastase Modulates Its Immune Functions. Mol Cell Proteomics 16, 1507-1527.

Magorivska I, Donczo B, Dumych T, Karmash A, Boichuk M, Hychka K, Mihalj M, Szabo M, Csanky E, Rech J et al. 2018. Glycosylation of random IgG distinguishes seropositive and seronegative rheumatoid arthritis. Autoimmunity 51, 111-117.

Nkurunungi G, van Diepen A, Nassuuna J, Sanya RE, Nampijja M, Nambuya I, Kabagenyi J, Serna S, Reichardt NC, van Ree R et al. 2019. Microarray assessment of $\mathrm{N}$-glycan-specific $\operatorname{lgE}$ and $\operatorname{lgG}$ profiles associated with Schistosoma mansoni infection in rural and urban Uganda. Sci Rep 9, 3522.

Reily C, Stewart TJ, Renfrow MB, Novak J. 2019. Glycosylation in health and disease. Nat Rev Nephrol 15, 346-366.

Sakae Y, Satoh T, Yagi H, Yanaka S, Yamaguchi T, Isoda Y, lida S, Okamoto Y, Kato K. 2017. Conformational effects of N-glycan core fucosylation of immunoglobulin G Fc region on its interaction with Fcgamma receptor IIIa. Sci Rep 7, 13780.

Sali A, Blundell TL. 1993. Comparative protein modelling by satisfaction of spatial restraints. J Mol Biol 234, 779-815.

Schachter H. 2009. Paucimannose N-glycans in Caenorhabditis elegans and Drosophila melanogaster. Carbohydr Res 344, 1391-1396.

Serna S, Etxebarria J, Ruiz N, Martin-Lomas M, Reichardt NC. 2010. Construction of $\mathrm{N}$-glycan microarrays by using modular synthesis and on-chip nanoscale enzymatic glycosylation. Chemistry 16, 13163-13175.

Serna S, Yan S, Martin-Lomas M, Wilson IB, Reichardt NC. 2011. Fucosyltransferases as synthetic tools: glycan array based substrate selection and core fucosylation of synthetic N-glycans. J Am Chem Soc 133, 1649516502.

Serna S, Hokke $\mathrm{CH}$, Weissenborn M, Flitsch S, Martin-Lomas M, Reichardt NC. 2013. Profiling glycosyltransferase activities by tritium imaging of glycan microarrays. Chembiochem 14, 862-869.

Simon F, Bork K, Gnanapragassam VS, Baldensperger T, Glomb MA, Di Sanzo S, Ori A, Horstkorte R. 2019. Increased Expression of Immature MannoseContaining Glycoproteins and Sialic Acid in Aged Mouse Brains. Int J Mol Sci 20

Stambuk T, Klasic M, Zoldos V, Lauc G. 2020. N-glycans as functional effectors of genetic and epigenetic disease risk. Mol Aspects Med 10.1016/j.mam.2020.100891, 100891.

Steentoft C, Vakhrushev SY, Joshi HJ, Kong Y, Vester-Christensen MB, Schjoldager KT, Lavrsen K, Dabelsteen S, Pedersen NB, Marcos-Silva L et al. 2013. Precision mapping of the human O-GalNAc glycoproteome through SimpleCell technology. EMBO J 32, 1478-1488.

Szabo E, Hornung A, Monostori E, Bocskai M, Czibula A, Kovacs L. 2019. Altered Cell Surface N-Glycosylation of Resting and Activated T Cells in Systemic Lupus Erythematosus. Int J Mol Sci 20 
Taganna J, de Boer AR, Wuhrer M, Bouckaert J. 2011. Glycosylation changes as important factors for the susceptibility to urinary tract infection. Biochem.Soc. Trans. 39, 349-354.

Thaysen-Andersen M, Venkatakrishnan V, Loke I, Laurini C, Diestel S, Parker BL, Packer NH. 2015. Human neutrophils secrete bioactive paucimannosidic proteins from azurophilic granules into pathogen-infected sputum. $J$ Biol Chem 290, 8789-8802.

Tjondro HC, Loke I, Chatterjee S, Thaysen-Andersen M. 2019. Human protein paucimannosylation: cues from the eukaryotic kingdoms. Biol Rev Camb Philos Soc 94, 2068-2100.

van Noort K, Nguyen DL, Kriechbaumer V, Hawes C, Hokke CH, Schots A, Wilbers RHP. 2020. Functional characterization of Schistosoma mansoni fucosyltransferases in Nicotiana benthamiana plants. Sci Rep 10, 18528.

Venkatakrishnan V, Thaysen-Andersen M, Chen SC, Nevalainen H, Packer NH. 2015. Cystic fibrosis and bacterial colonization define the sputum $\mathrm{N}$ glycosylation phenotype. Glycobiology 25, 88-100.

Wilbers RH, Westerhof LB, van Noort K, Obieglo K, Driessen NN, Everts B, Gringhuis SI, Schramm G, Goverse A, Smant G et al. 2017. Production and glyco-engineering of immunomodulatory helminth glycoproteins in plants. Sci Rep 7, 45910.

Zipser B, Bello-DeOcampo D, Diestel S, Tai M-H, Schmitz B. 2012. Mannitou monoclonal antibody uniquely recognizes paucimannose, a marker for human cancer, stemness, and inflammation. J Carbohydr Chem 31, 504-518.

\section{Figure legends}


A

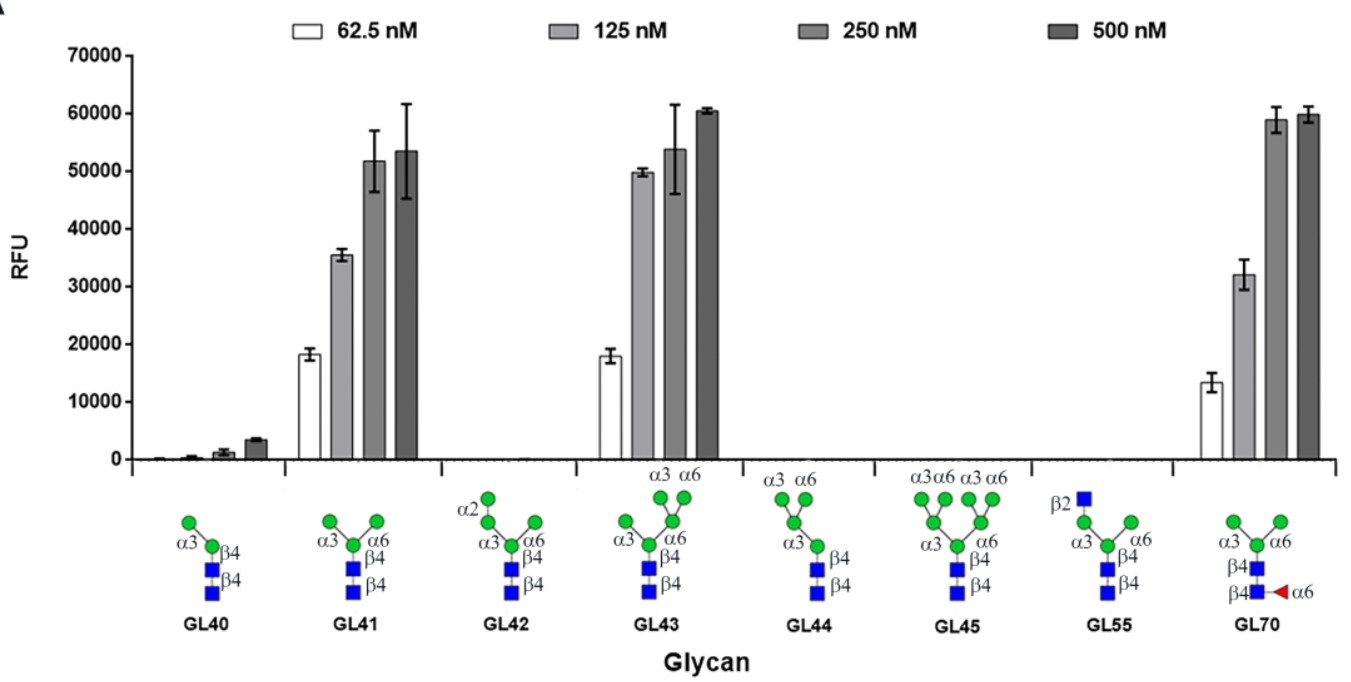

B

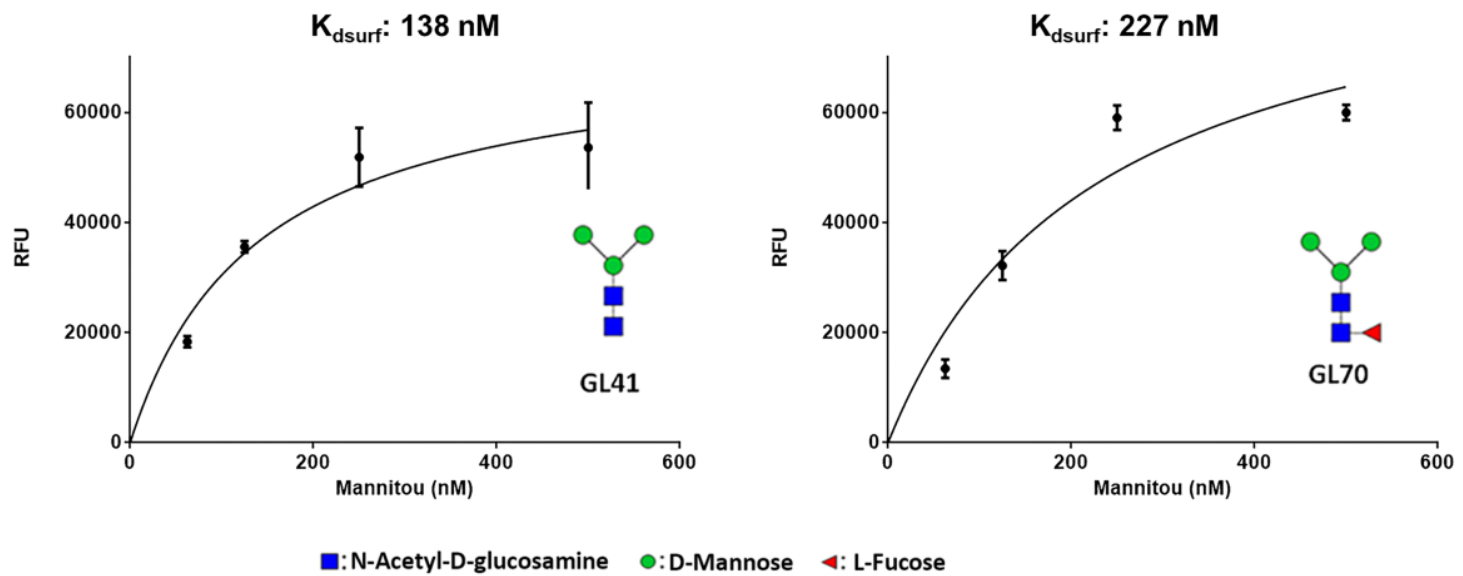

Figure 1. Mannitou IgM binding screening on the glycan microarray.

A. The binding of Mannitou IgM at different concentrations (62.5, 125, 250 and 500 $\mathrm{nM}$ ) to selected glycan structures is represented by its mean RFU (relative fluorescence units), with the standard deviation of the mean shown as error bars. B. Binding curves for the binding. of Mannitou IgM to M3GN2 and M3GN2F1(6). The data were fitted according to a 1:1 Langmuir binding model. 


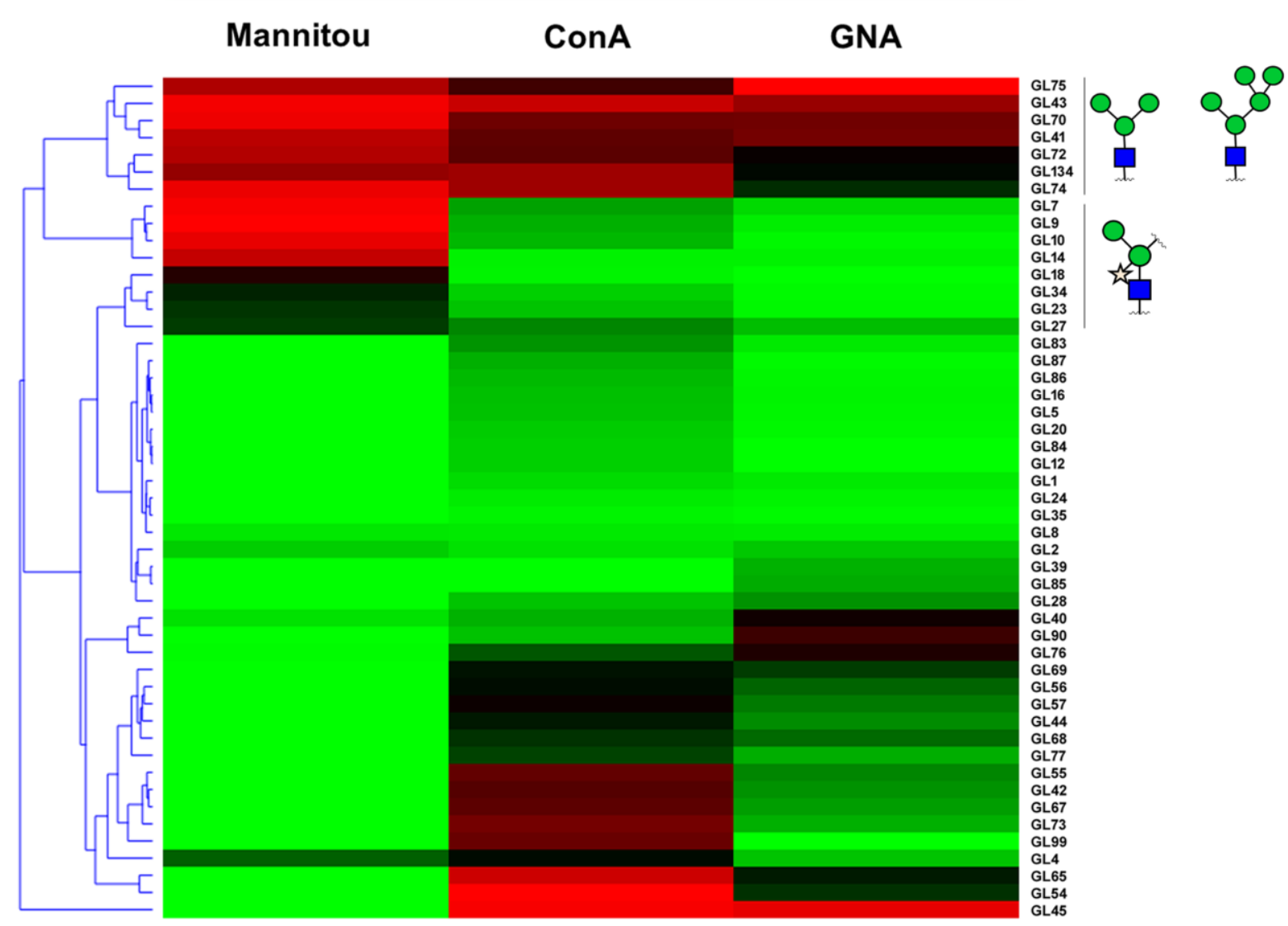

Figure 2. Dual color heat map representation of the normalized glycan microarray binding profiles of Mannitou, Concanavalin $A$ (ConA) and Galanthus nivalis agglutinin (GNA). Hierarchical clustering is based on Euclidean distance (average linkage method). For glycan structures, see Figure S1.

A

${ }_{600}^{R 0}$

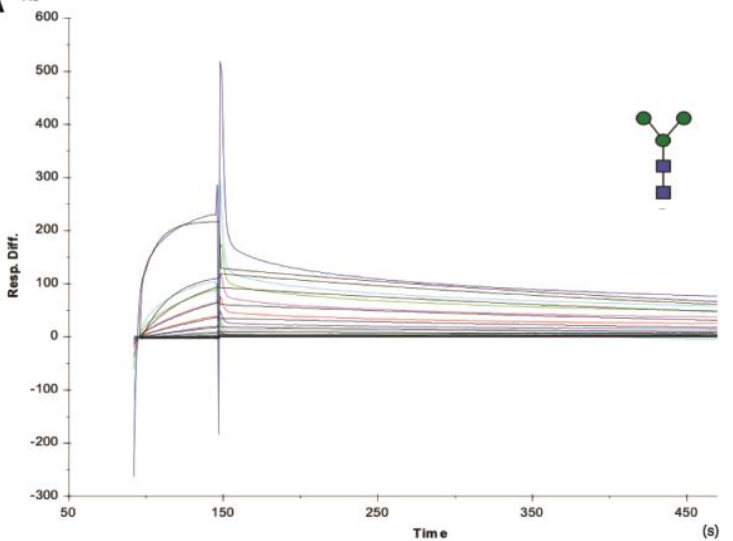

B

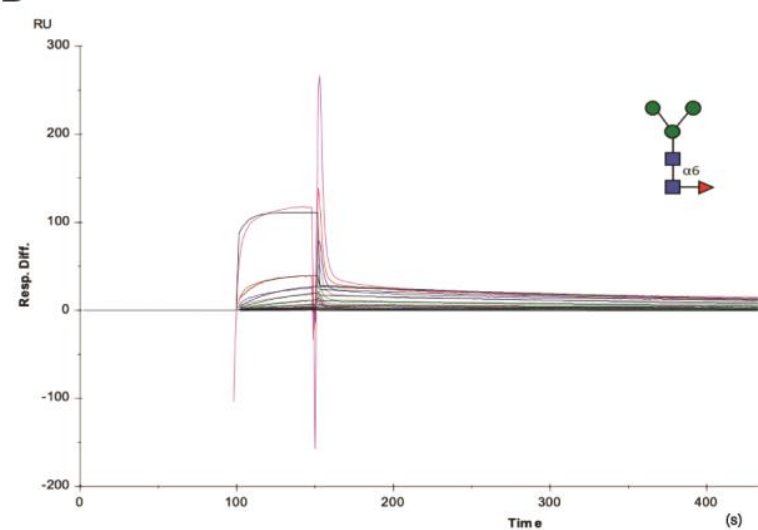

Figure 3. Kinetic binding experiments of Mannitou IgM to immobilized PMGs

SPR sensorgrams of a concentration series $(0.08-336 \mathrm{nM}$, coloured lines) of the IgM and fitting (black lines) to a 1:1 Langmuir binding model. (A) Fc2-Fc1 difference 
sensorgrams with $\mathrm{Man}_{3} \mathrm{GlcNAc}_{2}$ immobilised on Fc2. (B) Fc4-Fc3 difference sensorgrams with $\mathrm{Man}_{3} \mathrm{GlcNAc}_{2}(\alpha 1-6) F u c$ immobilized on Fc4. Fc1 and Fc3 are blank CM5 channels. Full regerenation between cycles was obtained using $50 \mathrm{mM}$ $\mathrm{NaOH}$. RU: Response Units.
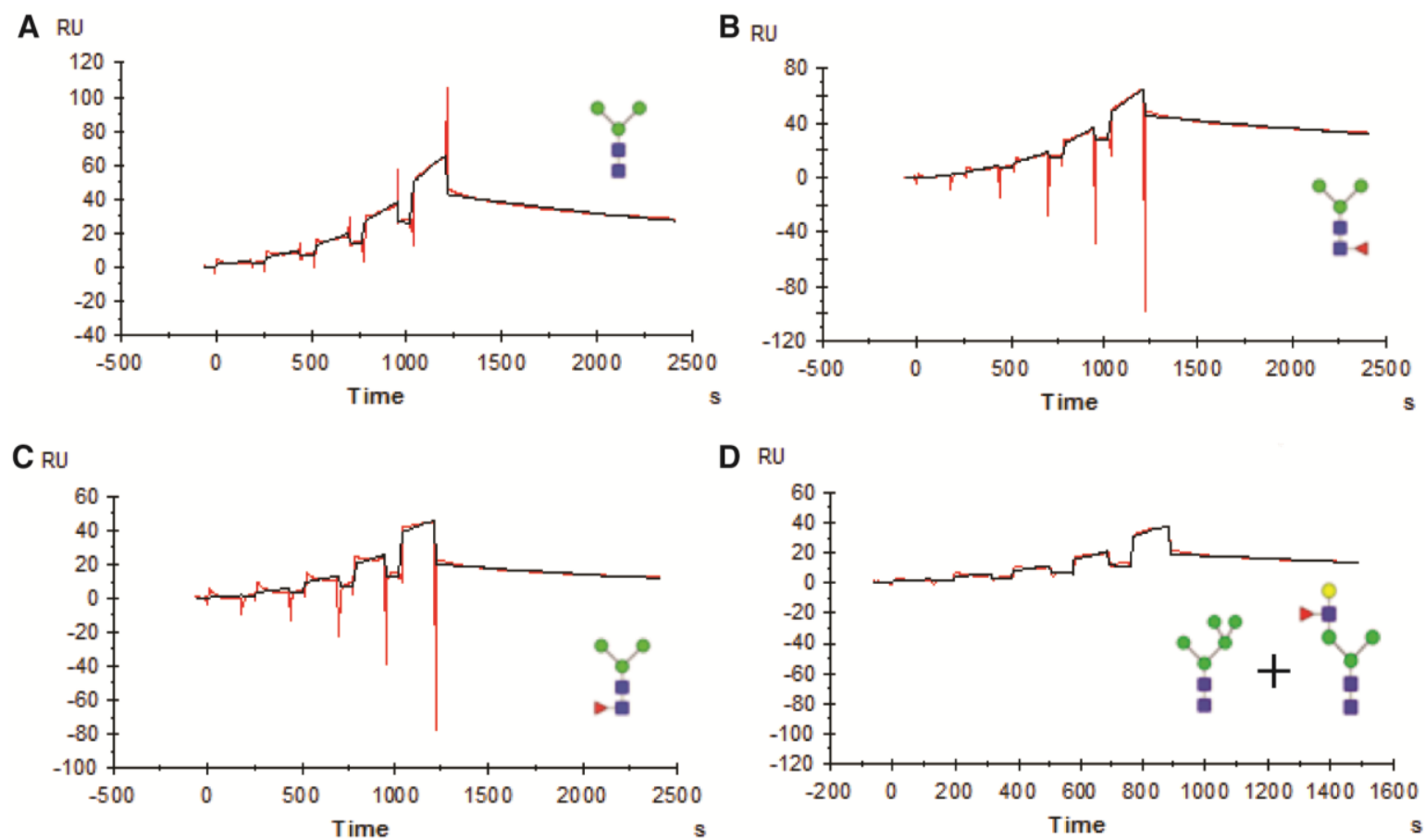

Figure 4. Kinetic binding experiments of Mannitou IgM to immobilized PMPs

Single cycle kinetics, or kinetic titration, of Mannitou lgM onto different PMPs, of which the major glycoform(s) is/are shown(n) in the inset (see experimental procedures for full details). Sensorgrams (red) after subtraction of non-binding kappa-5 M7GN2/M8GN2, see Figure S5) in Fc1 and fitting (black) according to a 1:1 Langmuir binding model. (A) $\omega 1$ M3GN2, (B) $\omega 1$ M3GN2F1(6), (C) $\omega 1$ M3GN2F1(3), (D) $\omega 1$ M5GN2 + Le $e^{x} \cdot R U:$ Response Units. 


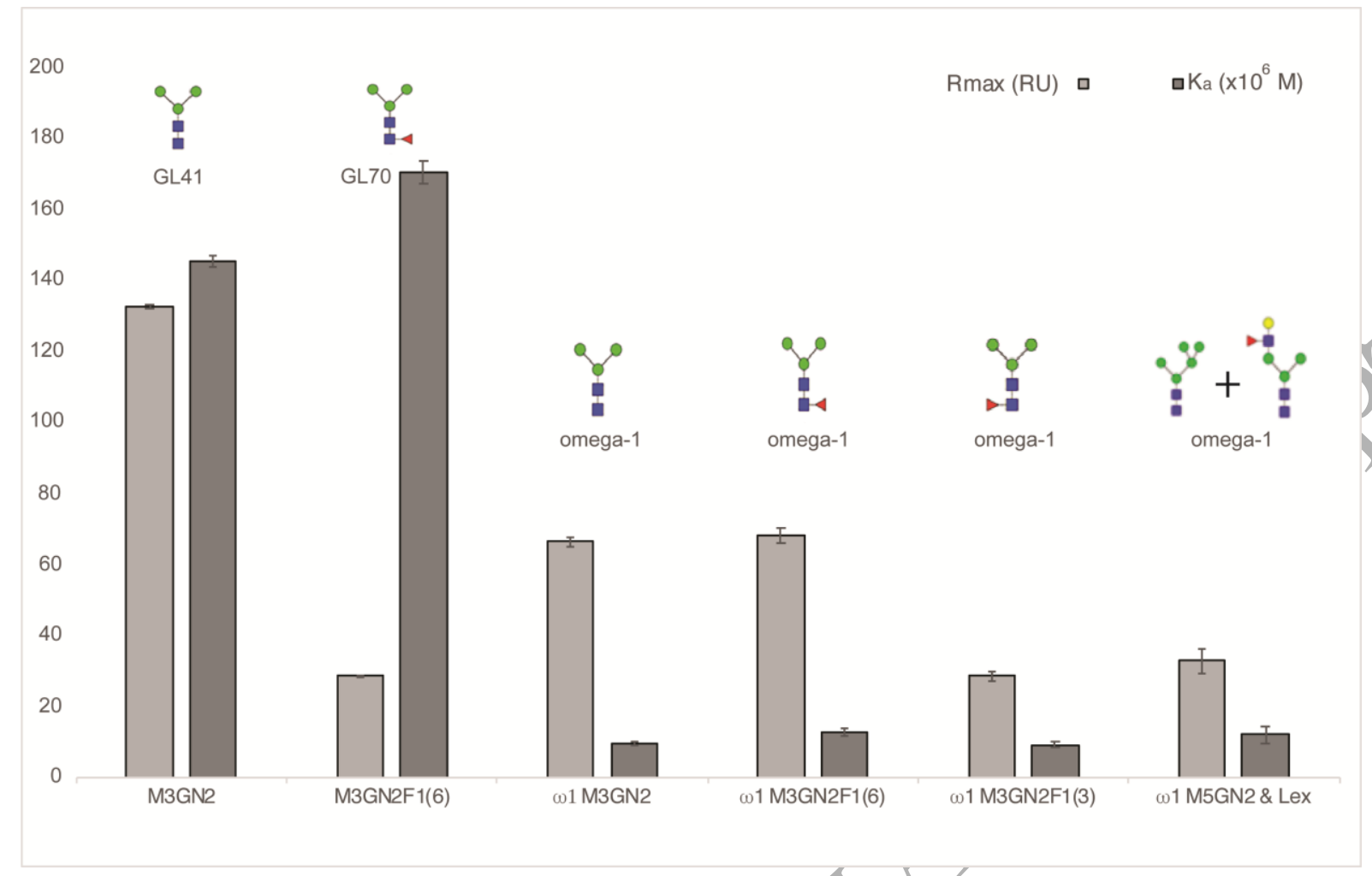

Figure 5. Comparison of PMP with PMG binding of Mannitou IgM

Maximal binding (Rmax, light grey) and affinities ( $K_{a}$, dark grey) of Mannitou IgM analyte for the two M3GN2 and M3GN2F1(6) PMG ligands, coupled via the aminopentyl spacer at their reducing end on the sensor chip (Figure S3), and comparison with their presentation as asparagine-linked $\mathrm{N}$-glycans on the immobilized omega-1 proteins. 


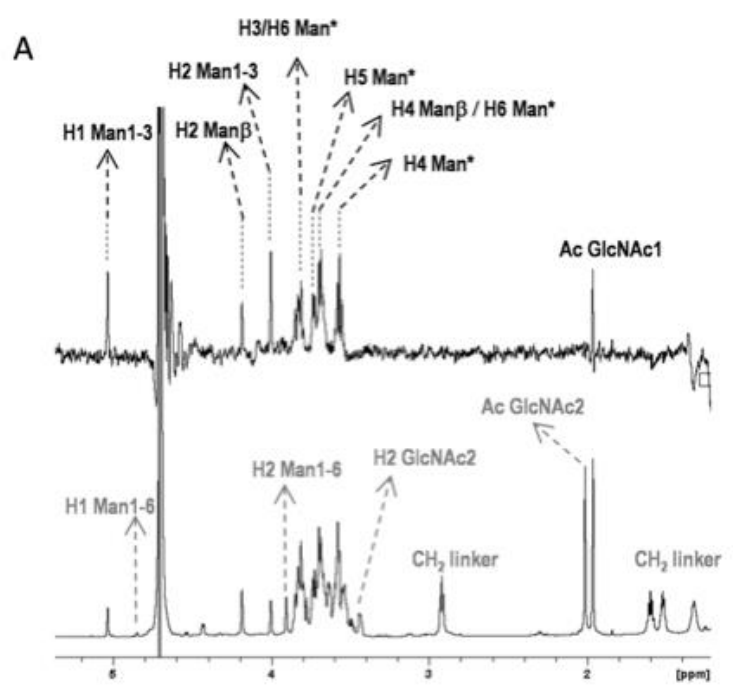

B

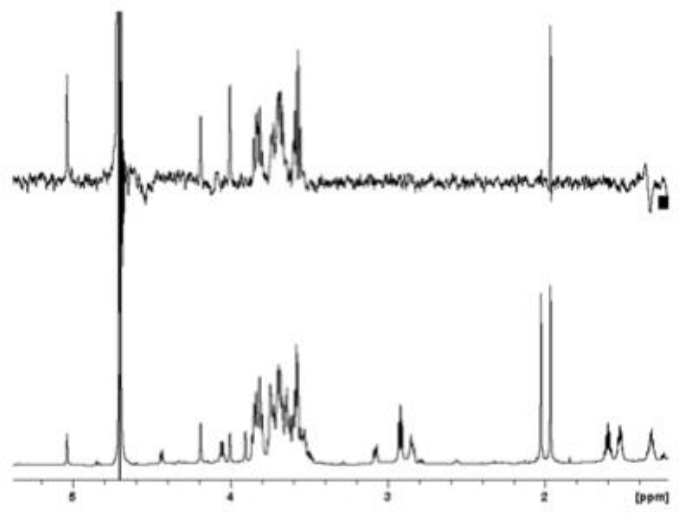

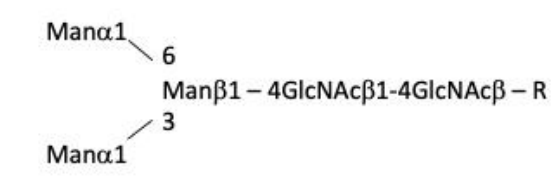

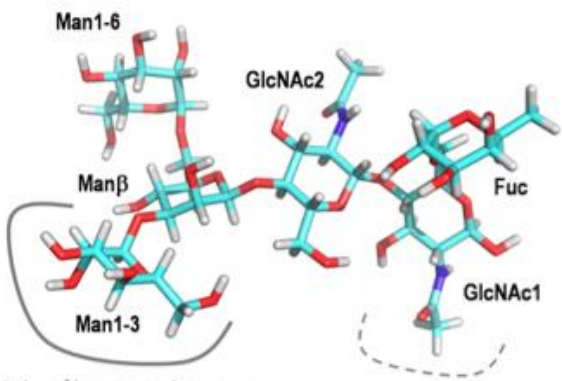

Binding epitope

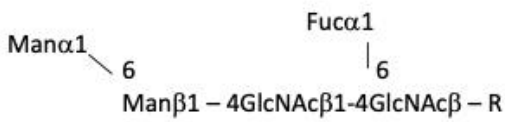

Man 11

Figure 6. PMG epitope for Mannitou antibody based on ${ }^{1} \mathrm{H}$-STD-NMR

\section{spectroscopy}

${ }^{1} \mathrm{H}$-STD experiments for Mannitou Fab $(25 \mu \mathrm{M})$ with glycan epitope $(1 \mathrm{mM})$ (A) $\mathrm{Man}_{3} \mathrm{GlcNAC}_{2}$ and (B) Man $\mathrm{GlCNAC}_{2}$ Fuc. In (A), protons of the glycan giving STD signals are labeled (black). Stars $\left({ }^{*}\right)$ indicate potentially overlapping protons from the a1-3- and a1-6-linked mannose. Protons that do not give any STD (non-overlapping) signals are labelled (grey) in the reference spectrum. A 3D-structural model of the interaction regions (indicated by thick grey lines) of M3GN2F1(6) was derived from the STDDD spectrum (top) and the off-resonance spectrum (bottom). It can be seen that the STDDD spectra in (A) and (B), respectively without and with the $\square$ 1-6 core fucose, are almost identical. 


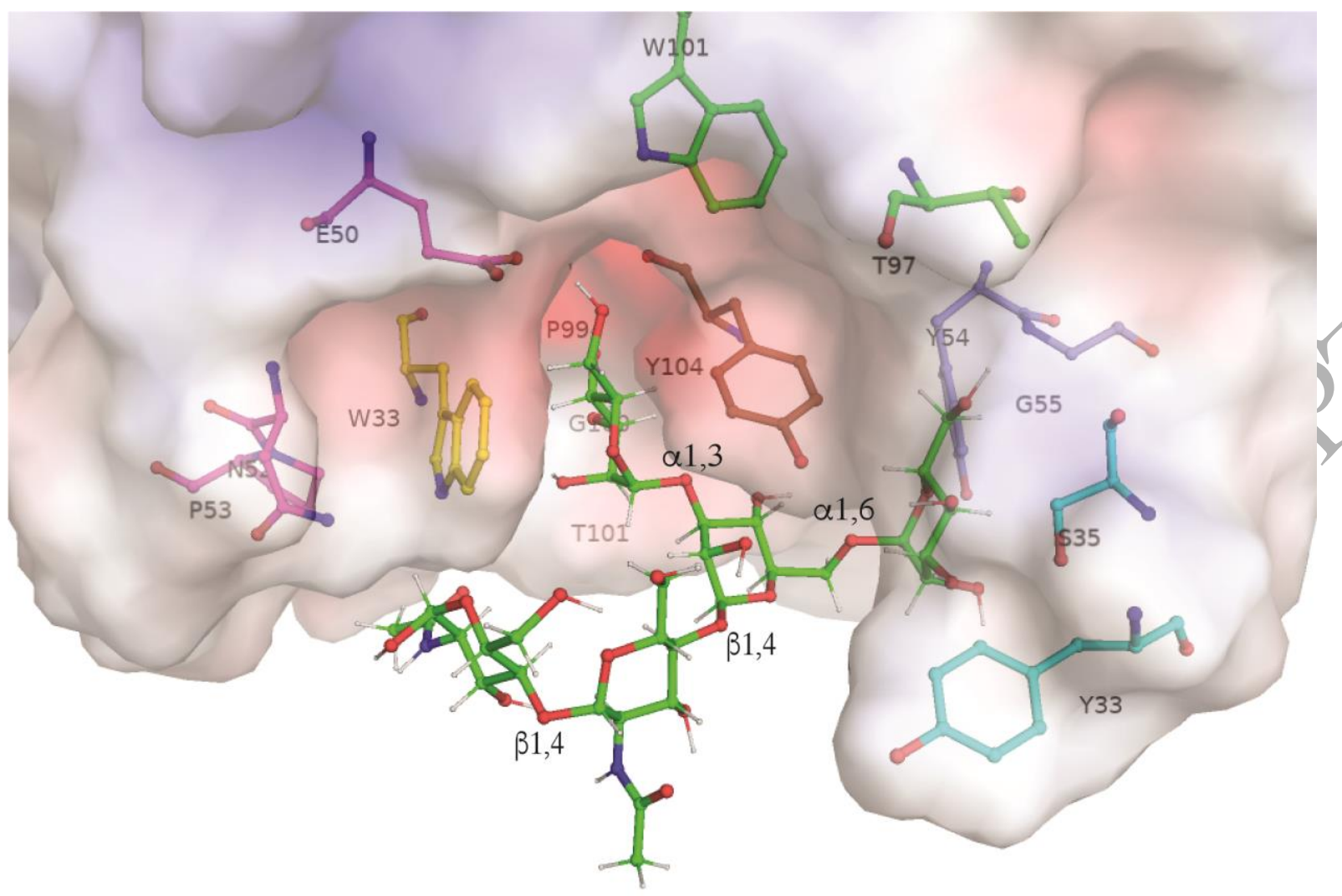

Figure 7. Positioning of M3GN2 into the Mannitou Fab homology model

Molecular docking between the Mannitou Fab 3D-model and $\mathrm{Man}_{3} \mathrm{GlcNAc}_{2}$ demonstrates the docking of the $\alpha 1-3$ mannose into a snug pocket. Residues are colored according to the CDR they belong to and identically as depicted on the sequenced IgM (Figure S7). Molecular presentation prepared using The PyMOL Molecular Graphics System, Version 2.0, from Schrödinger, LLC.

\begin{tabular}{|c|c|c|c|c|c|c|c|c|c|c|}
\hline Ligand & $\begin{array}{c}\text { Imm. } \\
\mathbf{R U}\end{array}$ & $\begin{array}{c}\mathbf{R}_{\max } \\
\mathbf{R U}\end{array}$ & $\begin{array}{c}\mathbf{S E}\left(\mathbf{R}_{\max }\right) \\
\mathbf{R U}\end{array}$ & $\begin{array}{c}\boldsymbol{k}_{\mathbf{a}} \\
\mathbf{M}^{-1} \cdot \mathbf{s}^{-\mathbf{1}}\end{array}$ & $\begin{array}{c}\mathbf{S E}\left(\boldsymbol{k}_{\mathrm{a}}\right) \\
\mathbf{M}^{-1} \cdot \mathbf{s}^{-1}\end{array}$ & $\begin{array}{c}\boldsymbol{k}_{\mathrm{d}} \\
\mathbf{s}^{-1}\end{array}$ & $\begin{array}{c}\mathbf{S E}\left(\boldsymbol{k}_{\mathrm{d}}\right) \\
\mathbf{M}^{-1} \cdot \mathbf{s}^{-1}\end{array}$ & $\begin{array}{c}\mathbf{K}_{\mathrm{d}} \\
\mathbf{n M}\end{array}$ & $\begin{array}{c}\mathbf{S E}\left(\mathbf{K}_{\mathrm{d}}\right) \\
\mathbf{n M}\end{array}$ & $\mathbf{C h i}^{2}$ \\
\hline M3GN2 & 237 & 132.5 & 0.5 & 300816 & 2142 & $2.07 \mathrm{E}-03$ & $1.72 \mathrm{E}-05$ & 6.87 & 0.08 & 26.86 \\
\hline M3GN2F1(6) & 163 & 28.7 & 0.2 & 470885 & 6304 & $2.77 \mathrm{E}-03$ & $3.51 \mathrm{E}-05$ & 5.87 & 0.11 & 4.33 \\
\hline
\end{tabular}

Table I: Immobilization rate and fitted global parameters for the kinetics of PMG binding by Mannitou IgM. SE: Standard Error. RU: Response Units.

\begin{tabular}{|c|c|c|c|c|c|c|c|c|c|c|}
\hline Ligand & $\begin{array}{c}\text { Imm. } \\
\text { RU }\end{array}$ & $\begin{array}{c}\mathbf{R}_{\max } \\
\mathbf{R U}\end{array}$ & $\begin{array}{c}\mathbf{S E}\left(\mathbf{R}_{\max }\right) \\
\mathbf{R U} \\
\end{array}$ & $\begin{array}{c}k_{\mathrm{a}} \\
\mathbf{M}^{-1} \cdot \mathbf{s}^{-1} \\
\end{array}$ & $\begin{array}{l}\operatorname{SE}\left(k_{\mathrm{a}}\right) \\
\mathbf{M}^{-1} \cdot \mathbf{s}^{-1}\end{array}$ & $\begin{array}{l}k_{\mathrm{d}} \\
\mathrm{s}^{-1}\end{array}$ & $\begin{array}{l}\mathrm{SE}\left(k_{\mathrm{d}}\right) \\
\mathbf{M}^{-1} \cdot \mathbf{s}^{-1}\end{array}$ & $\begin{array}{l}\mathbf{K}_{\mathbf{d}} \\
\mathbf{n M}\end{array}$ & $\begin{array}{c}\mathrm{SE}\left(\mathbf{K}_{\mathrm{d}}\right) \\
\mathrm{nM}\end{array}$ & $\mathrm{Chi}^{2}$ \\
\hline$\omega 1$ M3GN2 & 2324 & 66.4 & 1.5 & 3629 & 187 & $3.82 \mathrm{E}-4$ & $8.25 \mathrm{E}-06$ & 105 & 6 & 4.96 \\
\hline$\omega 1$ M3GN2F1(6) & 2061 & 68.0 & 2.2 & 4056 & 298 & $3.10 \mathrm{E}-4$ & $1.11 \mathrm{E}-05$ & 76.5 & 6.3 & 16.02 \\
\hline
\end{tabular}




\begin{tabular}{|l|c|c|c|c|c|c|c|c|c|c|}
\hline $\boldsymbol{\omega} 1$ M3GN2F1(3) & 2505 & 28.8 & 1.4 & 4374 & 388 & $4.67 \mathrm{E}-4$ & $1.84 \mathrm{E}-05$ & 107 & 10 & 11.56 \\
\hline $\boldsymbol{\omega} 1$ M5GN2 \& Le & 3271 & 32.9 & 3.6 & 7088 & 1181 & $5.78 \mathrm{E}-4$ & $5.53 \mathrm{E}-05$ & 81.6 & 15.7 & 14.38 \\
\hline
\end{tabular}

Table II: Immobilization rate and fitted global parameters for the kinetics of PMP binding by Mannitou

IgM. SE: Standard Error. RU: Response Units. 